\title{
Monetary Policy, Trend Inflation and the Great Moderation: An Alternative Interpretation
}

\author{
Olivier Coibion
}

\author{
Yuriy Gorodnichenko*
}

\begin{abstract}
With positive trend inflation, the Taylor principle does not guarantee a determinate equilibrium. We provide new theoretical results on determinacy in New Keynesian models with positive trend inflation and new empirical findings on the Federal Reserve's reaction function before and after the Volcker disinflation to find that 1) while the Fed likely satisfied the Taylor principle before Volcker, the US economy was still subject to self-fulfilling fluctuations in the 1970s, 2) the US economy switched to determinacy during the Volcker disinflation, and 3) the switch reflected changes in the Fed's response to macroeconomic variables and the decline in trend inflation.
\end{abstract}

Keywords: Trend inflation, Determinacy, Great Moderation, Monetary Policy, Disinflation. JEL: C22, E3, E43, E5

* Coibion, Department of Economics, College of William and Mary, 115 Morton Hall, Williamsburg, VA 23187-8795 (email: ocoibion@wm.edu); Gorodnichenko, Department of Economics, University of California at Berkeley, 693 Evans Hall, Berkeley, CA 94720-3880 (email: ygorodni@econ.berkeley.edu). We are grateful to three anonymous referees, Jean Boivin, Kathryn Dominguez, Jordi Gali, Pierre-Olivier Gourinchas, David Romer, and Carl Walsh, as well as seminar participants at the Bank of Canada, UC Berkeley, UC Santa Cruz, and SED for comments. We thank Eric Swanson for sharing the series of monetary policy surprises, Jean Boivin for sharing his code, and Viacheslav Sheremirov for excellent research assistance. All errors are ours. 
The pronounced decline in macroeconomic volatility since the early 1980s, frequently referred to as the Great Moderation, has been the source of significant debate. One prominent explanation for this phenomenon is that monetary policy became more "hawkish" with the ascent of Paul Volcker as Federal Reserve chairman in 1979. ${ }^{1}$ Originally proposed by John B. Taylor (1999) and Richard Clarida et al (2000), this view emphasizes that in the late 1960s and 1970s, the Fed systematically failed to respond sufficiently strongly to inflation, thereby leaving the US economy subject to self-fulfilling expectations-driven fluctuations. The policy reversal enacted by Volcker and continued by Greenspan—namely the increased focus on fighting inflationstabilized inflationary expectations and removed this source of economic instability. ${ }^{2}$ The theoretical argument is based on the Taylor principle: the idea that if the central bank raises interest rates more than one for one with inflation, then self-fulfilling expectations will be eliminated as a potential source of fluctuations. Yet point estimates of the Fed's response to inflation in the pre-Volcker era-regardless of whether they are less than one as in Clarida et al (2000) or greater than one as in Athanasios Orphanides (2004)—consistently come with such large standard errors that the issue of whether the US economy was indeed in a state of indeterminacy, and hence subject to self-fulfilling fluctuations, before Volcker remains unsettled.

In addition, recent theoretical work by Andreas Hornstein and Alexander L. Wolman (2005), Michael E. Kiley (2007) and Guido Ascari and Tiziano Ropele (2009), has cast additional doubt on the issue by uncovering an intriguing result: the Taylor principle breaks down when trend inflation is positive (i.e., the inflation rate in the steady state is positive).

\footnotetext{
${ }^{1}$ Other explanations emphasize inventory management or a change in the volatility of shocks. See e.g. James A. Kahn et al (2002) for the former and Alejandro Justiniano and Giorgio E. Primiceri (2008) for the latter.

2 This view has received recent support (see Thomas A. Lubik and Frank Schorfheide (2004) and Jean Boivin and Marc Giannoni (2006)). On the other hand, Orphanides $(2001,2002,2004)$ argues that once one properly accounts for the central bank's real-time forecasts, monetary policy-makers in the pre-Volcker era responded to inflation in much the same way as those in the Volcker and Greenspan periods so self-fulfilling expectations could not have been the source of instability in the 1970s.
} 
Using different theoretical monetary models, these authors all find that achieving a unique Rational Expectations Equilibrium (REE) at historically typical inflation levels requires much stronger responses to inflation than anything observed in empirical estimates of central banks' reaction functions. These results imply that the method of attempting to assess determinacy solely through testing whether the central bank raises interest rates more or less than one for one with inflation is insufficient: one must also take into account the level of trend inflation. For example, finding that the Fed's inflation response satisfied the Taylor principle after Volcker took office - as in Clarida et al (2000) - does not necessarily imply that self-fulfilling expectations could not still occur since the inflation rate averaged around three percent per year rather than the zero percent needed for the Taylor principle to apply. Similarly, the argument by Orphanides (2002) that monetary policy-makers satisfied the Taylor principle even before Volcker became chairman does not necessarily invalidate the conclusion of Taylor (1999) and Clarida et al (2000) that the US economy moved from indeterminacy to determinacy around the time of the Volcker disinflation: the same response to inflation by the central bank can lead to determinacy at low levels of inflation but indeterminacy at higher levels of inflation. Thus, it could be that the Volcker disinflation of 1979-1982, by lowering average inflation, was enough to shift the US economy from indeterminacy to the determinacy region even with no change in the response of the central bank to macroeconomic variables.

This paper offers two main contributions. First, we provide new theoretical results on the effects of endogenous monetary policy for determinacy in New Keynesian models with positive trend inflation. Second, we combine these theoretical results with empirical evidence on actual monetary policy to provide novel insight into how monetary policy changes may have affected the stability of the US economy over the last forty years. For the former, we show that determinacy in New Keynesian models under positive trend inflation depends not just on the 
central bank's response to inflation and the output gap, as is the case under zero trend inflation but also on many other components of endogenous monetary policy that are commonly found to be empirically important. Specifically, we find that interest smoothing helps reduce the minimum long-run response of interest rates to inflation needed to ensure determinacy. This differs substantially from the zero trend inflation case, in which inertia in interest rate decisions has no effect on determinacy prospects conditional on the long-run response of interest rates to inflation. We also find that price-level targeting helps achieve determinacy under positive trend inflation, even when the central bank does not force the price level to fully return to its target path. Finally, while Ascari and Ropele (2009) emphasize the potentially destabilizing role of responding to the output gap under positive trend inflation, we show that responding to output growth can help restore determinacy for plausible inflation responses. This finding provides new support for Carl E. Walsh (2003) and Orphanides and John C. Williams (2006), who call for monetary policy makers to respond to output growth rather than the level of the output gap. More generally, we show that positive trend inflation makes stabilization policy more valuable and calls for a more aggressive policy response to inflation even if an economy stays in the determinacy region.

The key implication of these theoretical results is that one cannot study the determinacy prospects of the economy without considering simultaneously 1) the level of trend inflation, 2) the Fed's response to inflation and its response to the output gap, output growth, price-level gap, and the degree of interest smoothing, and 3) the model of the economy. The second contribution of this paper is therefore to revisit the empirical evidence on determinacy in the U.S. economy taking into account these interactions using a two-step approach. In the first step, we estimate the Fed's reaction function before and after the Volcker disinflation. We follow Orphanides (2004) and use the Greenbook forecasts prepared by the Federal Reserve staff before 
each meeting of the Federal Open Market Committee (FOMC) as real-time measures of expected inflation, output growth, and the output gap. Like the previous literature, we find ambiguous results as to the hypothesis of whether the Taylor principle was satisfied before the Volcker disinflation depending on the exact empirical specification, with large standard errors that do not permit us to clearly reject this hypothesis. We also find that while the Fed's long-run response to inflation is higher in the latter period, the difference is not consistently statistically significant. Importantly, we uncover other ways in which monetary policy has changed. First, the persistence of interest rate changes has risen. Second, the Fed's response to output growth has increased dramatically, while the response to the output gap has decreased (although not statistically significantly). These changes, according to our theoretical results, make determinacy a more likely outcome.

In the second step, we combine the empirical distribution of our parameter estimates of the Taylor rule with a calibrated New Keynesian model and different estimates of trend inflation to infer the likelihood that the US economy was in a determinate equilibrium each period. We find that despite the substantial uncertainty about whether or not the Taylor principle was satisfied in the pre-Volcker era, the probability that the US economy was in the determinacy region in the 1970's is zero according to our preferred empirical specification. This reflects the combined effects of a response to inflation that was close to one, a non-existent response to output growth, relatively little interest smoothing, and, most importantly, high trend inflation over this time period. On the other hand, given the Fed's response function since the early 1980s and the low average rate of inflation over this time period, 3 percent, we conclude that the probability that the US economy has been in a determinate equilibrium since the Volcker disinflation exceeds 99 percent according to our preferred empirical specification. Thus, we concur with the original conclusion of Clarida et al (2000). However, whereas these authors 
reach their conclusion primarily based on testing for the Taylor principle over each period, we argue that the switch from indeterminacy to determinacy was due to several factors, none of which would likely have sufficed on their own. Instead, the higher inflation response combined with the decrease in the trend level of inflation account for much of the movement away from the indeterminacy region.

While our baseline results indicate that the US economy has most likely been within the determinacy region since the Volcker disinflation, we also find that higher levels of trend inflation such as those reached in the 1970s could bring the US economy to the brink of the indeterminacy region. In our counterfactual experiments, we find that the complete elimination of the Fed's current response to the output gap would remove virtually any chance of indeterminacy, even at 1970 s levels of inflation. But this does not imply that central banks should, in general, not respond to the real side of the economy. The last result holds only because, since Volcker, the Fed has been responding strongly to output growth. Were the Fed to stop responding to both the output gap and output growth, indeterminacy at higher inflation rates would become an even more likely outcome. Thus, a positive response to the real side of the economy should not necessarily be interpreted as central bankers being 'dovish' on inflation.

Our paper is closely related to Timothy Cogley and Argia Sbordone (2008). They find that controlling for trend inflation has important implications in the estimation of the New Keynesian Phillips Curve, whereas we conclude that accounting for trend inflation is necessary to properly assess the effectiveness of monetary policy in stabilizing the economy. In a sense, one may associate the end of the Great Inflation as a source of the Great Moderation. To support this view, we estimate a time-varying parameter version of the Taylor rule from which we extract a measure of time-varying trend inflation and construct a time series for the likelihood that the US economy was in the determinacy region. This series indicates that the probability of 
determinacy went from 0 percent in 1980 to 90 percent in 1984 , which is the date most commonly associated with the start of the Great Moderation (Margaret McConnell and Gabriel Perez-Quirós (2000)). Devoting more effort to understanding the determinants of trend inflation, as in Thomas J. Sargent (1999), Giorgio E. Primiceri (2006) or Peter Ireland (2007), and the Volcker disinflation of 1979-1982 in particular, is likely to be a fruitful area for future research.

Our approach is also very closely related to Lubik and Schorfheide (2004) and Boivin and Giannoni (2006). Both papers address the same question of whether the US economy has switched from indeterminacy to determinacy because of monetary policy changes, and both reach the same conclusion as us. However, our approaches are quite different. First, we emphasize the importance of allowing for positive trend inflation, whereas they abstract away from the implications of positive trend inflation. Second, we consider a larger set of policy responses for the central bank, which we argue has significant implications for determinacy as well. Third, we estimate the parameters of the Taylor rule using real-time Fed forecasts, whereas these papers impose rational expectations on the central bank in their estimation. Fourth, we allow for time-varying parameters in the Taylor rule as well as time-varying trend inflation. Finally, we draw our conclusions about determinacy by feeding our empirical estimates of the Taylor rule into a pre-specified model, whereas they estimate the structural parameters of the DSGE model jointly with the Taylor rule. ${ }^{3}$ Our approach instead allows us to estimate the parameters of the Taylor rule using real-time data while imposing as few restrictions as possible. We are then free to consider the implications of these parameters for any model. While much more flexible than estimating a DSGE model, our approach does have two key limitations. First, we are forced to select rather than estimate some parameter values for the model. Second,

\footnotetext{
${ }^{3}$ Estimation under indeterminacy requires selecting one out of many potential equilibrium outcomes. While various criteria can be used for this selection, how best to proceed in this case remains a point of contention. Our approach does not require us to impose any additional assumptions.
} 
because we do not estimate the shock processes, we cannot quantify the effect of our results as completely as in a fully specified and estimated DSGE model.

The paper is structured as follows. Section I presents the model, while section II presents new theoretical results on determinacy under positive trend inflation. Section III presents our Taylor rule estimates and their implications for US determinacy since the 1970s, as well as robustness exercises. Section IV concludes.

\section{Model and Calibration}

We rely on a standard New Keynesian model, in which we focus on allowing for positive trend inflation and a unit root for technology. In the interest of space, we present only the loglinearized equations. ${ }^{4}$ We use the model to illustrate the importance of positive trend inflation for determinacy of rational expectations equilibrium (REE) and point to mechanisms that can enlarge or reduce the region of determinacy for various policy rules.

\section{A. The Model}

The representative consumer maximizes the present discounted stream of utility over consumption and firm-specific labor, with the discount factor given by $\beta$. We assume utility is separable over labor and consumption with log-utility for consumption and a Frisch labor supply elasticity of $\eta$. We abstract from investment, government spending, and international trade (so consumption is equal to production of final goods). Hence, the dynamic IS equation is

$$
E_{t} g y_{t+1}=r_{t}-E_{t} \pi_{t+1}
$$

where $g y$ is the growth rate of output, $r$ is the nominal interest rate and $\pi$ is inflation, all expressed as deviations from the log of their steady-state values $\overline{G Y}, \bar{R}$, and $\bar{\Pi}$ respectively.

\footnotetext{
${ }^{4}$ The detailed model and all derivations can be found in Olivier Coibion and Yuriy Gorodnichenko (2008).
} 
The final good is a Dixit-Stiglitz aggregate over a continuum of measure one of intermediate goods. The elasticity of substitution across goods is given by $\theta$. Each intermediate good is produced by a monopolist using a standard production function over technology and firm-specific labor with constant returns to scale. Technology follows a random walk process as in Ireland (2004). Intermediate goods producers are allowed to reset prices each period with probability $1-\lambda$, as in Guillermo Calvo (1983). For a firm that is able to change its price at time $t$, the (log-linearized) optimal relative reset price $b_{t}$ is given by

$$
\begin{aligned}
& \left(1+\theta \eta^{-1}\right) b_{t}=\left(1+\eta^{-1}\right)\left(1-\gamma_{2}\right) \sum_{j=0}^{\infty} \gamma_{2}^{j} E_{t} x_{t+j} \\
& +E_{t} \sum_{j=1}^{\infty}\left(\gamma_{2}^{j}-\gamma_{1}^{j}\right)\left(g y_{t+j}-r_{t+j-1}\right)+\sum_{j=1}^{\infty}\left[\gamma_{2}^{j}\left(1+\theta\left(1+\eta^{-1}\right)\right)-\gamma_{1}^{j} \theta\right] E_{t} \pi_{t+j}
\end{aligned}
$$

where $\gamma_{1} \equiv \lambda \bar{R}^{-1} \overline{G Y} \bar{\Pi}^{\theta}, \gamma_{2} \equiv \gamma_{1} \bar{\Pi}^{1+\theta / \eta}$, and the output gap $x_{t}$ is defined as the log-deviation of output from the flexible-price equilibrium level of output. Note that under zero trend inflation, $\gamma_{2}=\gamma_{1}$. Consider how positive trend inflation affects the relative reset price. First, higher trend inflation raises $\gamma_{2}$, so that the weights in the output gap term shift away from the current gap and more towards future output gaps. This reflects the fact that as the relative reset price falls over time, the firm's future losses will tend to grow very rapidly. Thus, a sticky-price firm must be relatively more concerned with output gaps far in the future when trend inflation is positive. Second, the relative reset price now depends on the discounted sum of future differences between output growth and interest rates. Note that this term disappears when the log of trend inflation is zero: $\bar{\pi} \equiv \log \bar{\Pi}=0$. This factor captures the scale effect of aggregate demand in the future. The higher aggregate demand is expected to be in the future, the bigger the firm's losses will be from having a deflated price. The interest rate captures the discounting of future gains. When $\bar{\pi}=0$, these two factors cancel out. Positive $\bar{\pi}$, however, introduces the potential for much bigger losses in the future which makes these effects first-order. Third, positive $\bar{\pi}$ raises 
the coefficient on expected inflation. This reflects the fact that the higher is expected inflation, the more rapidly the firm's price will depreciate, the higher it must choose its reset price. Thus, positive trend inflation makes firms more forward-looking in their price-setting decisions by raising the importance of future marginal costs and inflation, as well as by inducing them to also pay attention to future output growth and interest rates.

The relationship between inflation and the relative reset price is given by

$$
\pi_{t}=\left(\frac{1-\lambda \bar{\Pi}^{\theta-1}}{\lambda \bar{\Pi}^{\theta-1}}\right) b_{t}
$$

Note that higher levels of trend inflation make inflation less sensitive to the current reset price because, on average, firms who change prices set them above the average price level and therefore account for a smaller share of expenditures than others. Finally, given our assumption of a unit root process for technology, the relationship between actual output and the output gap is such that

$$
g y_{t}=x_{t}-x_{t-1}+\varepsilon_{t}^{a}
$$

where $\varepsilon_{t}^{a}$ is the innovation to technology at time $t^{5}$

\section{B. Parameterization}

Allowing for positive trend inflation increases the state space of the model and makes analytical solutions infeasible. Thus, all of our determinacy results are numerical. We calibrate the model as follows. The Frisch labor supply elasticity, $\eta$, is set to 1 . We let $\beta=0.99$ and the steady-state growth rate of real GDP per capita be 1.5 percent per year $\left(\overline{G Y}=1.015^{0.25}\right)$, which matches the

\footnotetext{
${ }^{5}$ Sticky-price models with positive trend inflation typically require that one keep track of the dynamics of price dispersion. We do not need to do so here because we express the reset price equation in terms of the output gap rather than aggregate marginal costs. It is easy to show that the relationship between firm-specific and aggregate marginal costs is a function of aggregate price dispersion, but as shown in Coibion and Gorodnichenko (2008), the link between firm-specific marginal costs and the output gap is not. Hence, we do not explicitly model the dynamics of price dispersion. Note that this result is sensitive to the structure of the model: if we assume homogeneous labor supply rather than firm-specific labor supply, then the reset price equation is necessarily a function of price dispersion and we must keep track of the dynamics of price dispersion in solving the model.
} 
U.S. rate from 1969 to 2002 . The elasticity of substitution $\theta$ is set to 10 , which corresponds to a markup of 11 percent. This size of the markup is consistent with estimates presented in Craig Burnside (1996) and Susanto Basu and John G. Fernald (1997). Finally, the degree of price stickiness $(\lambda)$ is set to 0.55 , which amounts to firms resetting prices approximately every 7 months on average. This is midway between the micro estimates of Mark Bils and Peter J. Klenow (2004), who find that firms change prices every 4 to 5 months, and those of Emi Nakamura and Jón Steinsson (2008), who find that firms change prices every 9 to 11 months. We will investigate the robustness of our results to these parameters in subsequent sections.

\section{Equilibrium Determinacy under Positive Trend Inflation}

To close the model, we need to specify how monetary policy-makers set interest rates. One common description is a simple Taylor rule, expressed in log-deviations from steady-state values:

$$
r_{t}=\phi_{\pi} E_{t} \pi_{t+j}
$$

in which the central bank sets interest rates as a function of contemporaneous $(j=0)$ or future $(j>0)$ inflation. As documented in Woodford (2003), such a rule, when applied to a model like the one presented here, with zero trend inflation yields a simple and intuitive condition for the existence of a unique rational expectations equilibrium: $\phi_{\pi}>1$. This result, commonly known as the Taylor Principle, states that central banks must raise interest rates by more than one-forone with (expected) inflation to eliminate the possibility of sunspot fluctuations.

Yet, as emphasized in Hornstein and Wolman (2005), Kiley (2007), and Ascari and Ropele (2009), the Taylor principle loses its potency in environments with positive trend inflation. The top left panel in Figure 1 presents the minimum response of the central bank to inflation necessary to ensure the existence of a unique rational expectations equilibrium for a 
contemporaneous $(j=0)$ Taylor rule. As found by Hornstein and Wolman (2005), Kiley (2007), and Ascari and Ropele (2009), the basic Taylor principle breaks down when the trend inflation rate rises. With a contemporaneous Taylor rule, after inflation exceeds 1.2 percent per year, the minimum response needed by the central bank starts to rise. With trend inflation of 6 percent a year, as was the case in the 1970 s, the central bank would have to raise interest rates by almost ten times the increase in the inflation rate to sustain a determinate REE. Note that this result is not limited to Calvo pricing. Hornstein and Wolman (2005) and Kiley (2007) find similar results using staggered contracts a la Taylor (1977). ${ }^{6}$

In the rest of this section, we investigate how modifications of the basic Taylor rule affect the prospects for a determinate equilibrium under positive trend inflation. First, we reproduce the results of Hornstein and Wolman (2005), Kiley (2007), and Ascari and Ropele (2009) that focus on adding a response to the output gap. Second, we provide new results on the determinacy implications of responding to output growth. Third, we investigate the determinacy implications of adding inertia to the policy rule via an interest smoothing motive and via price level targeting. Finally, we demonstrate that positive trend inflation generally requires stronger responses by the central bank to achieve stabilization than under zero trend inflation within the determinacy region.

\section{A. Responding to the Output Gap}

One variation on the basic Taylor rule which has received much attention in the literature is to allow for the central bank to respond to the output gap as follows

$$
r_{t}=\phi_{\pi} E_{t} \pi_{t+j}+\phi_{x} E_{t} x_{t+j}
$$

\footnotetext{
${ }^{6}$ In Coibion and Gorodnichenko (2008), we replicate all of our theoretical results using forward-looking Taylor rules as well as staggered price setting and find qualitatively similar results.
} 
Woodford (2003) shows that in a model similar to the one presented above with zero trend inflation, a contemporaneous $(j=0)$ Taylor rule will ensure a determinate REE if $\left(\phi_{\pi}+\frac{1-\beta}{\kappa} \phi_{x}\right)>$ 1 which is commonly known as the Generalized Taylor Principle. ${ }^{7}$ This result follows from the fact that in the steady-state, there is a positive relationship between inflation and the output gap. Yet Kiley (2007) and Ascari and Ropele (2009) demonstrate that this extension of the Taylor principle breaks down with positive trend inflation because the slope of the New Keynesian Phillips Curve (NKPC) turns negative for sufficiently high levels of trend inflation. The top right panel in Figure 1 presents the minimum response to inflation necessary to achieve determinacy for different levels of trend inflation and different responses to the output gap. Small but positive responses to the output gap lead to lower minimum responses to inflation to achieve determinacy, as was the case with zero trend inflation. However, stronger responses to the output gap (generally greater than 0.5 ) have the opposite effect and require bigger responses to inflation to sustain a unique REE. Hence, with positive trend inflation, strong responses to the output gap can be destabilizing rather than stabilizing. ${ }^{8}$

\section{B. Responding to Output Growth}

The results for responding to the output gap under positive trend inflation call into question whether central banks should respond to the real side of the economy at all, even when one ignores the uncertainty regarding real-time measurement issues. Yet recent work by Walsh (2003) and Orphanides and Williams (2006) has emphasized an alternative real variable that monetary policy makers can respond to for stabilization purposes: output growth. To determine

\footnotetext{
${ }^{7}$ In our model, $\kappa \equiv(1-\lambda)(1-\beta \lambda) /\left[\lambda\left(1+\theta \eta^{-1}\right)\right]$.

${ }^{8}$ These results also apply if we consider a response by the central bank to the deviation of output from its trend rather than from the flexible price equilibrium level of output, as demonstrated in Coibion and Gorodnichenko (2008).
} 
how such a "speed limit" policy might affect determinacy with trend inflation, we consider the following Taylor rule

$$
r_{t}=\phi_{\pi} E_{t} \pi_{t+j}+\phi_{g y} E_{t} g y_{t+j}
$$

The bottom left panel in Figure 1 presents the minimum response to inflation needed by the central bank to ensure determinacy for different trend inflation rates and responses to output growth. Having the central bank respond to output growth helps ensure determinacy of the equilibrium, with the minimum level of inflation response needed for determinacy falling as the response to output growth increases. In fact, a more general principle seems to be at work here: determinacy appears to be guaranteed for any positive trend inflation rate when the Fed responds to both inflation and current output growth by more than one-for-one. There are two channels through which responding to output growth helps achieve determinacy. First, responding to the output growth rate effectively makes the policy reaction function history-dependent because it responds to lagged output. Second, responding to expected output growth amplifies the central bank's response to inflation. Using the dynamic IS equation, we find that a permanent increase in inflation $d \pi$ leads to a permanent increase in the real interest rate $d r-d \pi=\frac{\phi_{\pi}-1}{1-\phi_{g y}} d \pi$ when $\phi_{\pi}>1$ and $0 \leq \phi_{g y}<1$, and therefore higher expected GDP growth via the IS equation. Intuitively, higher expected output growth raises the real interest rate when $\phi_{g y}>0$ which further lowers output and raises expected output growth. The size of the multiplier for the increase in real interest rates is given by $1 /\left(1-\phi_{g y}\right)$. Thus, targeting real variables is not automatically destabilizing under positive trend inflation. Instead, strong responses to output 
growth help restore the basic Taylor principle whereas strong responses to the output gap can be destabilizing. ${ }^{9}$

\section{Interest Rate Smoothing}

An additional extension to the basic Taylor rule which has become exceedingly common is to allow for interest smoothing as follows

$$
r_{t}=\rho r_{t-1}+(1-\rho) \phi_{\pi} E_{t} \pi_{t+j}
$$

where $\rho$ is the degree of interest smoothing. In this case, $\phi_{\pi}$ can be interpreted as the long-run response of interest rates to a permanent one-percentage point increase in inflation. As shown in Woodford (2003), such rules are also consistent with the Taylor principle, requiring that the long-run response to inflation $\phi_{\pi}$ be greater than one for any degree of interest smoothing between 0 and 1 . Thus, under zero trend inflation, interest smoothing has no effect on determinacy of the equilibrium, conditional on the long-run response of interest rates to inflation. On the other hand, super-inertial rules (in which $\rho \geq 1$ ) guarantee determinacy for any positive response to inflation, since these imply an infinite long-run response of interest rates to permanent changes in inflation.

We investigate the effect of introducing interest smoothing in the Taylor rule under positive trend inflation in the bottom right panel of Figure $1 .{ }^{10}$ Higher interest smoothing makes determinacy sustainable at lower levels of $\phi_{\pi}$. With interest smoothing of the order of 0.9 , a value frequently found in empirical work, the Taylor principle is restored for inflation rates as high as 6 percent. This differs from the zero trend inflation case: under positive trend inflation,

\footnotetext{
${ }^{9}$ While "speed limit" policies are sometimes expressed in terms of responses to the growth rate of the output gap rather than the growth rate of output, this distinction is irrelevant for determinacy issues. This is because the growth rate of the output gap is equal to the growth rate of output minus the innovation to technology. Thus, substituting the growth rate of the gap into the Taylor rule, then substituting out the growth in the gap with the growth in output yields an identical response of the central bank to endogenous variables, thereby yielding the same determinacy region.

${ }^{10}$ Note that for $\rho=1$, we rewrite the Taylor rule as $r_{t}=r_{t-1}+\phi_{\pi} E_{t} \pi_{t+j}$.
} 
interest smoothing helps achieve determinacy even conditional on the long-run response to inflation. This suggests that history-dependence is particularly useful in improving the determinacy properties of interest rate rules when $\bar{\pi}>0$. In addition, super-inertial rules (in which $\rho \geq 1$ ) continue to guarantee determinacy for any positive response to the inflation rate, exactly as was the case with $\bar{\pi}=0$.

\section{Price Level Targeting}

Another policy approach often considered in the literature is price-level targeting (PLT). To model this, we follow Gorodnichenko and Matthew D. Shapiro (2007) and write the Taylor rule as

$$
r_{t}=\phi_{p} d p_{t}
$$

where $d p_{t}$ is the log deviation of the price level $\left(P_{t}\right)$ from its target path $\left(P_{t}^{*}\right)$

$$
d p_{t} \equiv \ln P_{t}-\ln P_{t}^{*}=\delta d p_{t-1}+\pi_{t} .
$$

The price gap depends on the lagged price gap and the current deviation of inflation from the target. The parameter $\delta$ indicates how "strict" price-level targeting is. In the case of $\delta=0$, the price-level gap is just the deviation of inflation from its target and the Taylor rule collapses to the basic inflation targeting case. When $\delta=1$, we have strict price level targeting in which the central bank acts to return the price level completely back to the target level after a shock. The case of 0 $<\delta<1$ is "partial" price level targeting, in which the central bank forces the price level to return only partway to the original target path. By quasi-differencing the Taylor rule after substituting in the price gap process, one can readily show that this policy is equivalent to the following Taylor rule:

$$
r_{t}=\delta r_{t-1}+\phi_{p} \pi_{t}
$$


which is observationally equivalent to the basic Taylor rule with interest smoothing. Thus, when the central bank pursues strict PLT $(\delta=1)$, this is equivalent to the central bank having a superinertial rule. Determinacy is therefore guaranteed for any positive response to the price level (and therefore inflation). Thus, the result of Woodford (2003) that strict PLT guarantees determinacy in a Calvo type model with zero trend inflation continues to hold (at least numerically) under positive trend inflation. In addition, partial PLT $(0<\delta<1)$ will yield the exact same results as interest smoothing. The stricter the PLT (the higher the $\delta$ ), the smaller the longrun response to inflation will need to be to sustain a determinate REE for positive trend levels of inflation.

\section{E. Positive Trend Inflation and Economic Stabilization within the Determinacy Region}

While all of our results have focused on the determinacy implications of positive trend inflation, one can also consider the effects of trend inflation on economic stabilization within the determinacy region. Specifically, the question we want to address is how strongly the central bank should respond to inflation under positive trend inflation to achieve the same welfare from stabilization as under zero trend inflation. To assess the welfare gains due to stabilization policies under zero and positive trend inflation, we derive the second order approximation to the consumer utility function augmented with external habit formation in consumption when $\bar{\pi}$ can differ from zero. ${ }^{11,12}$

\footnotetext{
${ }^{11}$ S. Boragan Aruoba and Schorfheide (2009) investigate how trend inflation affects social welfare in the steady state. The first order effects documented in that paper are not dependent on our policy rules which are functions of deviations of inflation, output gap or any other relevant variable from the steady state. Hence, our analysis is more informative about the value of stabilization policies. Stephanie Schmitt-Grohé and Martin Uribe (2007) consider the benefits of stabilization policies with positive trend inflation. However, their calibration imposes that 80 percent of firms can reset prices every period and that the elasticity of demand is relatively low implying low strategic complementarity. With this calibration, positive trend inflation set at low levels as calibrated in Schmitt-Grohé and Uribe (2007) is not likely to lead to any significant departures from the standard Taylor principle, which is consistent with our robustness analysis below. Ascari and Ropele (2007) evaluate the effects of inflation and output gap variability given positive trend inflation. Our analysis is different in two key respects. First, they postulate a loss
} 
Proposition 1: The second order approximation to consumer utility

$$
\max E_{t} \sum_{j=0}^{\infty} \beta^{j}\left[\ln \left(\frac{C_{t+j}}{H_{t+j}^{h}}\right)-\left(1+\eta^{-1}\right)^{-1} \int_{0}^{1} N(i)_{t+j}^{1+\eta^{-1}} d i\right]
$$

is given by

$$
\begin{aligned}
& \frac{1-\beta h}{1-\beta}\left[(1+\eta) \operatorname{var}\left(x_{t}\right)\right. \\
& \left.\quad+\left\{Q_{1, y} \frac{\theta-1}{\theta}+(1+\eta)\left(1+\frac{\theta-1}{\theta} Q_{1, y} Q_{0, y}\right)\right\} \frac{(1-\lambda) M^{2}+\lambda}{1-\beta \lambda} \operatorname{var}\left(\pi_{t}\right)\right]
\end{aligned}
$$

where $\quad Q_{1, y}=\left[1-\frac{1}{2}\left(\frac{\theta-1}{\theta}\right)^{2} \bar{\Upsilon}\right] /\left[1+\frac{1}{2}\left(\frac{\theta-1}{\theta}\right)^{2} \bar{\Upsilon}\right]^{3}, \quad Q_{0, y}=\left[\frac{1}{2}\left(\frac{\theta-1}{\theta}\right) \bar{\Upsilon}\right] /\left[1+\frac{1}{2}\left(\frac{\theta-1}{\theta}\right)^{2} \bar{\Upsilon}\right]^{2}, \quad \bar{\Upsilon}=$ $\operatorname{Evar}_{i}\left(\log \left(y_{t}(i) / Y_{t}^{F}\right)\right)=\theta^{2} \bar{\pi}^{2} \lambda /(1-\lambda)^{2}, M=\lambda \bar{\Pi}^{\theta-1} /\left(1-\lambda \bar{\Pi}^{\theta-1}\right), h$ is the degree of habit formation in consumption, and $H_{t}$ is the exogenously determined ("external") habit which is equal to lagged consumption.

Proof: see Coibion and Gorodnichenko (2008).

It is straightforward to show that, for any plausible calibration of $\theta, \lambda, \eta$ and $\bar{\pi}$, the weight on inflation variability increases with the level of trend inflation $\bar{\pi}$. Hence, the central result of this proposition is that positive trend inflation makes stabilization (specifically with respect to inflation) more valuable. This finding is intuitive: the level of cross-sectional price dispersion increases with positive trend inflation and hence more variable inflation has a larger effect on welfare.

function rather than derive it as a second order approximation to consumer utility. Second, they consider policies under discretion or commitment while we analyze Taylor-type rules.

${ }^{12}$ Note that technology shocks are the only economic disturbance in our model. Without habit formation, permanent innovations to the level of technology have no effects on inflation or the output gap. We also experimented with using specifications where there are transitory changes in technology and no habit formation and obtained qualitatively similar results. 
Using the second order approximation to consumer utility and the contemporaneous Taylor rule as in equation (2), we can assess what policy response $\phi_{\pi}$ is required to maintain a fixed level of expected utility as trend inflation $\bar{\pi}$ increases. ${ }^{13}$ Let us define $\phi_{\pi \mid \bar{\pi}, U}$ as the minimal policy response necessary to achieve utility level $U$ given trend inflation $\bar{\pi}$. Figure 2 shows the ratio $\phi_{\pi \mid \bar{\pi}, U} / \phi_{\pi \mid 0, U}$ for different $\bar{\pi}$ where $U$ is equal to the level of utility a policymaker can achieve with the lowest $\phi_{\pi}$ which yields determinacy at 6 percent trend inflation, the highest level of trend inflation in our analysis. Irrespective of what degree of habit formation $h$ we choose, the policymaker must be increasingly aggressive to inflation as $\bar{\pi}$ rises. We conclude that the key effect of positive trend inflation on determinacy, i.e. requiring stronger responses to inflation by the central bank, also generally applies within the parameter space in which determinacy occurs.

\section{Monetary Policy and Determinacy since the 1970s}

Under positive trend inflation, the Taylor principle is no longer a sufficient condition for determinacy, which implies that exercises focusing only on the inflation response in a Taylor rule will in general be insufficient to answer whether this rule is consistent with a determinate equilibrium. ${ }^{14}$ The previous section shows that one must simultaneously take into account all of the response coefficients of the central bank's policy function, the level of trend inflation, and the model. In this section, we revisit the issue of how monetary policy may have changed before and after the Volcker disinflation and whether any such changes may have moved the economy

\footnotetext{
${ }^{13}$ When we compare utility for different levels of trend inflation, we focus only on the terms which depend on stabilization policies. We ignore the first order effects of trend inflation on welfare because they do not depend on stabilization policy.

${ }^{14}$ Troy Davig and Eric M. Leeper (2007) argue that the possibility of the central banker switching to a policy rule consistent with determinacy (good policy) can lead to determinant outcomes even during times when the central banker's policy rule is not sufficiently aggressive to guarantee determinacy (bad policy). In other words, the possibility of switching to the good policy mitigates the effects of the bad policy. However, Davig and Leeper observe that the bad policy will still lead to increased volatility of macroeconomic variables. Hence, we continue to associate periods of bad policy with periods of increased volatility.
} 
out of an indeterminate equilibrium in the pre-Volcker era in light of how determinacy results hinge on the trend inflation rate. In section A, we estimate policy reaction functions for each time period. In section $\mathrm{B}$, we feed the estimated parameters of the policy rules into our model to assess the determinacy implications of the differences in response coefficients across the two periods given different trend inflation rates. Section $\mathrm{C}$ considers counterfactual experiments to study which changes in the policy rule have been most important and what further changes the Federal Reserve could pursue to strengthen the prospects of achieving determinacy. In section D, we allow for time-varying parameters in the policy rule from which we can extract a timevarying measure of trend inflation. By combining our implied measure of trend inflation and the time-varying parameters of the policy rule with our model, we construct a time series of the probability of the US economy being in a state of determinacy since the late 1960s. In section E, we investigate the robustness of our baseline determinacy results to parameter values and alternative price setting assumptions.

\section{A. Estimation of the Federal Reserve's Reaction Function}

Our baseline empirical specification for the Fed's reaction function is a generalized Taylor rule in which we assume there is a single break in trend inflation as well as in the coefficients of the response function around the time of the Volcker disinflation. Our baseline period-specific estimated Taylor rule is thus

$$
r_{t}=c+\left(1-\rho_{1}-\rho_{2}\right)\left(\phi_{\pi} E_{t} \pi_{t+j}+\phi_{g y} E_{t} g y_{t+j}+\phi_{x} E_{t} x_{t+j}\right)+\rho_{1} r_{t-1}+\rho_{2} r_{t-2}+\varepsilon_{t}
$$

where $\varepsilon_{t}$ is an error term. This specification allows for interest smoothing of order two, as well as a response to inflation, output growth, and the output gap. Allowing for responses to both the output gap and output growth is necessary because the two have different implications for 
determinacy with positive trend inflation. ${ }^{15}$ The constant term $c$ consists of the steady-state level of the interest rate, plus the (constant) level of trend inflation, as well as the target levels of output growth and output gap. To estimate equation (6), we follow Orphanides (2004) and use real-time data for the estimation. Specifically, we use the Greenbook forecasts of current and future macroeconomic variables prepared by staff members of the Fed a few days before each FOMC meeting. The interest rate is the target federal funds rate set at each meeting, from Christina D. Romer and David H. Romer (2004). The measure of the output gap is based on Greenbook forecasts, as compiled by Orphanides (2003, 2004). Data are available from 1969 to 2002 for each official meeting of the FOMC. We consider two time samples: 1969-1978 and 1983-2002. We drop the period from 1979 to 1982 in which the Federal Reserve officially abandoned interest rate targeting in favor of targeting monetary aggregates. Each $t$ is a meeting of the FOMC. From 1969-1978, meetings were monthly, whereas from 1983 on, meetings were held every 6 weeks. Note that this implies that the interest smoothing parameters in the Taylor rule are not directly comparable across the two time periods. ${ }^{16}$

Table 1 presents results of the least squares estimation of equation (6) over each time period for three cases: contemporaneous Taylor rule, forward-looking Taylor rule, and mixed. ${ }^{17}$

\footnotetext{
${ }^{15}$ We show in Coibion and Gorodnichenko (2008) that allowing for PLT yields similar conclusions as specifications without.

${ }^{16}$ John Cochrane (2007) argues that the central bank's response to inflation will be unidentified in New Keynesian models when the Taylor rule includes a stochastic intercept term that corresponds to the natural rate of interest, i.e. the rate of interest that would hold in the frictionless economy. However, Eric Sims (2008) shows that Cochrane's argument holds only if the central bank is responding one-for-one to fluctuations in the natural rate of interest, an unlikely scenario due to the inherent difficulty in measuring the natural rate of interest, particularly in real time. More generally, the Fed may be stabilizing inflation with off-equilibrium path threats that may not be observed in equilibrium. However, in practice, periods of apparent indeterminacy in the policy rule have come when trend inflation is high. Thus it is highly unlikely that the Fed has effectively been using off-equilibrium strategies over this period to stabilize inflation.

${ }^{17}$ We think there are several reasons why estimation by least squares (LS) is likely to be adequate. First, Hausman tests indicate that instrumental variable estimation leads to same results as LS, which indicates the exogeneity assumption is likely to be satisfied. Second, if Greenbook forecasts were made under assumptions about future policy actions that were systematically overturned, then these forecasts would be inferior to those made by agents who made better projections of future policy actions, such as professional forecasters. Yet Romer and Romer (2000) document that Greenbook forecasts of inflation systematically outperform professional forecasters. Third, we can
} 
In the case of the contemporaneous Taylor rule, we use the central bank's forecast of values for the current quarter. In the case of the forward-looking rule, we use the forecast of the average value over the next two quarters (but three quarter ahead forecast for the output gap). We find that interest rate decisions are best modeled (in terms of fitting the data) as a function of forecasts of future inflation but forecasts of the contemporaneous output gap and output growth rate. ${ }^{18}$ We will treat this specification as the baseline in subsequent sections. In addition to point estimates, standard errors and selected statistics of fit, we report the sum of the interest smoothing parameters converted to a quarterly frequency. ${ }^{19}$ We also include the probability value of the null that each of the parameters and the sum of interest smoothing parameters are the same in the two periods.

We find that the Fed's response to inflation in the pre-Volcker era satisfied the Taylor principle in forward-looking specifications, but not under the contemporaneous Taylor rule. Because the forward-looking specification is statistically preferred to a contemporaneous response to inflation, our evidence supports the argument of Orphanides (2004) that the Fed satisfied the Taylor principle in both periods, albeit weakly so. Like Orphanides, we also find that while our estimates consistently point to a stronger response by the Fed to inflation in the latter period, we can only reject the null of no change in the response to inflation in the case of the mixed rule. Thus, our estimates of the Fed's response coefficients do not provide strong

augment the right-hand-side of equation (6) with a direct measure of monetary policy innovations from Refet Gürkaynak, Brian Sack and Eric Swanson (2005), who identify monetary policy innovations by comparing Fed Funds Futures markets predictions of FOMC decisions with actual decisions. Adding this variable eliminates the omitted variable bias and hence LS are consistent. We found that estimates in this augmented specification are remarkably close to the specification without policy shocks identified via Fed Funds Futures. Details are available in Coibion and Gorodnichenko (2008).

18 Specifically, we consider all possible variants of forward-looking and contemporaneous-looking choices for inflation, output gap, and output growth responses and use the AIC to select the best specification.

${ }^{19}$ Because there is no convenient formula for converting AR(2) parameters from monthly or 6-weekly frequency to quarterly, we use the following approach: given estimated $\operatorname{AR}(2)$ parameters, we simulate an $\operatorname{AR}(2)$ process at the original frequency, and then create a new (average) series at the quarterly frequency. We then regress the quarterly series on two lags of itself over a sample of 50,000 periods and report the sum of the estimated parameters. 
support for the claims of Taylor (1999) and Clarida et al (2000) that the failure to satisfy the basic Taylor principle before Volcker placed the US economy in an indeterminate region. However, we do find that other response coefficients have changed in statistically significant ways. First, interest rate decisions have become more persistent, in the sense that the sum of the autoregressive components is higher in the latter period than in the early period, and statistically significantly so in two out of three specifications. Second, the Federal Reserve has changed how it responds to the real side of the economy. Whereas the period before the Volcker disinflation was characterized by a strong long-run response to the output gap, but no statistically discernible response to output growth, the period since the Volcker disinflation displays much stronger longrun responses by the Fed to output growth than to the output gap. Interestingly, all of the policy changes made by the Fed since the Volcker disinflation-stronger response to output growth and inflation, more interest smoothing, and weaker response to output gap (albeit not statistically significantly so for the latter)—will tend to make determinacy more likely.

\section{B. Determinacy Before and After the Volcker Disinflation}

To assess the implications of our estimated response functions, we feed the estimated parameters from each Taylor rule into the model described and calibrated in section I.B to examine the determinacy implications of monetary policy over the two samples. We first consider whether the model yields a determinate rational expectations equilibrium (REE) given the estimated parameters of the Taylor rule for two trend inflation rates -3 percent and 6 percent - designed to replicate average inflation rates in each of the two time periods. In addition, we consider how determinacy varies over the statistical distribution of our parameter estimates. For each type of Taylor rule and each sample period, we draw 10,000 times from the distribution of the estimated parameters and assess the fraction of draws that yield a determinate rational expectations 
equilibrium at 3 percent and 6 percent trend inflation. The results are presented in the bottom panel of Table $1 .^{20}$

First, we find that the pre-1979 response of the central bank implied an indeterminate REE given the average inflation rate of that time (6 percent). This is a very robust implication of the Taylor rule estimates: both the contemporaneous and mixed Taylor rules yield zero percent of draws consistent with determinacy while the forward-looking rule delivers a probability of determinacy of only 12 percent, despite a point estimate of 1.75 for the Fed's response to expected inflation. On the other hand, the post-1982 response is consistent with a determinate REE at the low average inflation rate of this period (3 percent). Using our preferred specification, the mixed Taylor rule, more than 99 percent of the empirical distribution of parameters yields determinacy. Thus, like Taylor (1999), Clarida et al (2000) and others, we find that monetary policy before Volcker led to indeterminacy in the 1970s, but that since 1982 the Fed's response has helped ensure determinacy.

Our approach also allows us to assess the relative importance of the change in the Fed's response function versus the change in trend inflation for altering the determinacy status of the economy. For example, had the Fed maintained its pre-1979 response function but lowered average inflation from 6 percent to 3 percent per year (via a change in the inflation target in the Taylor rule), the US economy would have remained in the indeterminacy region of the parameter space. Thus, the Volcker disinflation, during which average inflation was brought down, would have been insufficient to guarantee determinacy without a change in the Fed's response function as well. Similarly, we also find that the Fed's response to macroeconomic variables since 1982,

\footnotetext{
${ }^{20}$ Before feeding estimated parameters into the model, we first convert the interest smoothing parameter into a quarterly frequency and divide the coefficient on the output gap by four, since the Taylor rules are estimated using annualized rates, the Taylor rule in the model is written in terms of quarterly rates, and the output gap is scale invariant.
} 
while consistent with determinacy at 3 percent trend inflation, is only marginally consistent with determinacy at the inflation rate of the 1970s, with only sixty percent of draws from the distribution of estimated parameters from the mixed Taylor rule predicting determinacy at this inflation rate. Thus, the estimated parameters are near the edge of the parameter space consistent with a unique REE. This implies that if the Fed in the 1970s had simply switched to the current policy rule without simultaneously engaging in the Volcker disinflation, it is quite possible that the US economy would have remained subject to self-fulfilling expectations-driven fluctuations. The shift from indeterminacy to determinacy thus appears to have been due to two major policy changes: a change in the policy rule and a decline in the inflation target of the Federal Reserve during the Volcker disinflation.

\section{Counterfactual Experiments}

In this section, we perform counterfactual experiments designed to isolate the contribution of each policy change for determinacy, the results of which are presented in Table 2. Consider first the effect of switching the Fed's response to inflation $\phi_{\pi}$ across the two time periods. For the pre-1979 period at 6 percent trend inflation, this has no effect on determinacy, meaning that the fraction of draws from the empirical distribution of parameter estimates yielding a determinate REE is essentially unchanged at 0 percent. This means that if the only policy change enacted by the Fed had been to raise its response to inflation to the post-1982 level, but leaving its other response coefficients and the trend inflation unchanged, the US economy would have remained in an indeterminate equilibrium. Thus, while our findings support the argument of Clarida et al (2000) that the US moved from indeterminacy to determinacy during the Volcker disinflation, we emphasize not just the change in the Fed's response to inflation, which by itself was not enough to shift the US economy out of the indeterminacy of the 1970s, but rather that this policy 
change combined with the Volcker disinflation can account for much of the movement away from indeterminacy. Specifically, we find that if the Fed had maintained its pre-Volcker policy rule but used the post-1982 inflation response, then this single policy switch combined with the Volcker disinflation would have raised the likelihood of determinacy to about two-thirds.

We also consider the implication of switching the degree of interest smoothing across periods and the response to output growth, both of which are statistically different in the two time periods (see Table 1). For interest smoothing, we find almost identical results as in the baseline case, indicating that the increased inertia of interest rate decisions since the Volcker disinflation cannot account for the change in determinacy across periods. Switching the response to output growth across the two periods has a more important effect. If we start with the estimated post-1982 policy reaction function and switch $\phi_{g y}$ to its pre-1979 value, the fraction of draws yielding determinacy in the post-1982 period at 3 percent (6 percent) trend inflation would have been only 91 percent ( 26 percent) instead of 99 percent (62 percent). On the other hand, starting from the pre-1979 policy rule and raising $\phi_{g y}$, to the post-1982 level has almost no effect on determinacy. This indicates that the change in $\phi_{g y}$ complemented the other policy changes in terms of restoring determinacy, but could not, by itself, account for the reversal in determinacy around the time of the Volcker disinflation.

Finally, we consider the effect of the decrease in the Fed's response to the output gap, a policy difference strongly emphasized by Orphanides (2004), although we cannot reject the null of no change in the Fed's response to the gap across time periods. We find that if the post-1982 Fed had responded as strongly to the output gap as they did before Volcker, then the likelihood of the US economy being in the indeterminacy region would be somewhat higher, particularly at higher rates of inflation. At 6 percent trend inflation, the fraction of draws yielding determinacy 
falls from 62 percent to 33 percent. Thus, this result supports the emphasis placed by Orphanides (2004) on the lower response to the output gap by the Fed since the Volcker era, but for a different reason. Orphanides stresses that if the output gap is mismeasured in real-time, then a strong response to the output gap, like that followed by the Fed in the 1970s, can be destabilizing. Our interpretation is instead that even if the output gap is perfectly measured by the central bank, strong responses to the output gap can be destabilizing by raising the probability of indeterminacy.

We can extend our analysis by investigating how the central bank can further minimize the likelihood of indeterminacy. Thus, we consider determinacy prospects using each policy rule but imposing $\phi_{x}=0 .^{21}$ In the post-1982 period, eliminating the response to the output gap would raise the likelihood of determinacy significantly. This is most clearly visible at the 6 percent inflation rate, when eliminating the Fed's response to the output gap would raise the probability of determinacy from 62 to 99 percent. Thus, while the Fed has improved determinacy prospects somewhat by reducing its response to the output gap since the 1970s, a complete elimination of this response would be better yet. Importantly, this does not imply that the Federal Reserve is best served by not responding to the real side of the economy. Consider the counterfactual of no response by the Fed to both the output gap and output growth in each time period. In the post-1982 period, the prospects for determinacy are lower than in the case with just zero response to the output gap, particularly at higher inflation rates. For the latter, eliminating any response to the real side of the economy yields determinacy in less than 13 percent of draws, instead of the 99 percent when only the response to the output gap is eliminated. Thus, the current strong response to output growth by the Federal Reserve is well-

\footnotetext{
${ }^{21}$ Here, we draw from each period's distribution of parameters, then impose that the relevant coefficient be exactly zero for each draw.
} 
justified, and would play an important stabilizing role were the Fed to completely eliminate responding to the output gap. Furthermore, a positive response to the real side of the economy should not necessarily be interpreted as central bankers being "dovish" on inflation.

\section{Time-Varying Trend Inflation}

Our baseline estimation approach assumes that trend inflation, as well as the central bank's target for real GDP growth and the output gap, is constant within each time period. In this section, we relax these assumptions and extract a measure of trend inflation which allows us to construct a time series for the probability of determinacy for the U.S. economy. Our approach follows Boivin (2006), who estimates a similar Taylor rule with time-varying coefficients. We generalize the Taylor rule in equation (6) to:

$$
\begin{aligned}
r_{t}=\bar{\pi}_{t}+\omega_{t}+ & \left(1-\rho_{1, t}-\rho_{2, t}\right)\left[\phi_{\pi, t}\left(E_{t} \pi_{t+j}-\bar{\pi}_{t}\right)+\phi_{g y, t}\left(E_{t} g y_{t+j}-\overline{g y}_{t}\right)\right. \\
& \left.+\phi_{x, t}\left(E_{t} x_{t+j}-\bar{x}_{t}\right)\right]+\rho_{1, t}\left(r_{t-1}-\bar{\pi}_{t}-\omega_{t}\right)+\rho_{2, t}\left(r_{t-2}-\bar{\pi}_{t}-\omega_{t}\right)+\varepsilon_{t}
\end{aligned}
$$

where $\bar{\pi}_{t}$ is the target rate of inflation, $\omega_{t}$ is the equilibrium real interest rate, $\overline{g y}_{t}$ is the target rate of growth of real GDP, and $\bar{x}_{t}$ is the target level of the output gap. We can rewrite this as

$$
\begin{aligned}
r_{t}=c_{t} & +\left(1-\rho_{1, t}-\rho_{2, t}\right)\left(\phi_{\pi, t} E_{t} \pi_{t+j}+\phi_{g y, t} E_{t} g y_{t+j}+\phi_{x, t} E_{t} x_{t+j}\right) \\
& +\rho_{1, t} r_{t-1}+\rho_{2, t} r_{t-2}+\varepsilon_{t}
\end{aligned}
$$

where the time-varying constant term is given by

$$
c_{t}=\left(1-\rho_{1, t}-\rho_{2, t}\right)\left[\left(1-\phi_{\pi, t}\right) \bar{\pi}_{t}+\omega_{t}-\phi_{g y, t} \overline{g y}_{t}-\phi_{x, t} \bar{x}_{t}\right] .
$$

To estimate the parameters of equation (7), we follow Boivin (2006) and assume that each of the parameters follows a random walk process and allow for two breaks in the volatility of shocks to the parameters: 1979 and 1982. Using the Kalman filter and the corresponding smoother, we construct time series of the response coefficients of the Taylor rule and of the time-varying constant. 
The results for the estimated parameters, including the time-varying constant, are presented in Figure 3, along with one standard deviation confidence intervals. The results broadly confirm those in the baseline estimation: namely, there was a sharp increase in the Fed's response to inflation and output growth around the time of the Volcker disinflation, as well as a rise in the degree of interest smoothing, and there was little change in the response to the output gap once one allows for time-varying parameters. In addition, the time-varying parameters allow us to paint a more nuanced picture of monetary policy in the pre-Volcker era. Specifically, the estimated coefficients in 1969 are remarkably similar to those for the 1990s with strong responses to output growth and inflation, but there was a discernible change in the Fed's response function in the early 1970s that was reversed during the Volcker disinflation.

To extract a measure of trend inflation from the time-varying constant, we make additional assumptions about the equilibrium real interest rate and the Fed's targets for real GDP growth and the output gap. We follow Sharon Kozicki and Peter A. Tinsley (2009) and approximate the equilibrium real interest rate, the target growth rate of real GDP, and the target output gap by using the Hodrick-Prescott filter over each time period to extract a trend measure of each series, which we then feed into equation (8), along with estimates of time-varying parameters, to extract our measure of trend inflation. The bottom right panel of Figure 3 presents our (smoothed) estimate of the latter, along with one standard deviation confidence intervals. This measure of time-varying trend inflation paints a similar picture of changes in monetary policy as the response coefficients. Namely, at the start of the sample, the Fed's target rate of inflation was low, around 3 percent, and rose slightly over the early 1970's. Starting around 1975, we see a substantial increase in the Fed's target inflation, which peaks at approximately 8 percent in 1978. Thus, the data point to increasing accommodation of inflationary pressures by the Federal Reserve in the mid to late 1970s. The latter is reversed during the Volcker 
disinflation, after which target inflation is progressively reduced to 2 percent by the early 2000's. This behavior of trend inflation is remarkably consistent with the estimates of Cogley et al (forthcoming) and Ireland (2007) despite the differences in approaches.

Given the estimated time series of the Fed's response coefficients and our measure of trend inflation, we can construct a time series of the probability of determinacy for the U.S. economy given the estimated distribution of parameters in the Taylor rule (7). We do this under three alternative assumptions. The first is to allow for time-varying response coefficients but impose a constant rate of 3 percent trend inflation. The second is identical except that we impose a constant rate of 6 percent trend inflation. The third approach again uses time-varying response coefficients but also makes use of our time-varying estimate of trend inflation. The results are presented in Figure 4. Looking first at the estimates using time-varying trend inflation, the results from our baseline estimation are re-confirmed: the U.S. economy was very likely in a state of indeterminacy before the Volcker disinflation but not thereafter. Again, the use of timevarying parameters provides a more detailed perspective on the pre-Volcker era. At the start of our sample period, the probability of determinacy was close to one, reflecting the low estimate of trend inflation at the time as well as the strong responses to inflation and output growth. However, we can observe a rapid deterioration in the stabilization properties of monetary policy in the early 1970s such that by 1975 the probability of the U.S. economy being in a state of determinacy was less than ten percent. This was not reversed until the Volcker disinflation, since which the probability of determinacy has exceeded eighty percent. This finding is consistent with the view laid out in Romer and Romer (2002) emphasizing that good policy prevailed during Martin's chairmanship of the Fed (which ended in 1970) and returned with Volcker's ascent. 
The results with time-varying parameters also confirm the key role played by changes in the level of trend inflation in accounting for the apparent transition from determinacy to indeterminacy in the early 1970 s and then back to determinacy during the Volcker disinflation. Consider the first transition in the early 1970s. Our estimates imply that if the Fed had only changed the coefficients of its response function but held the target rate of inflation constant at 3 percent, the economy would have been right at the edge of the indeterminacy region, implying that the change in trend inflation accounts for approximately half of the switch from determinacy to indeterminacy over this time period. After the Volcker disinflation, the results are similar: had the Fed only changed its response coefficients but left its target inflation in the neighborhood of six percent, the probability of indeterminacy would still have been around fifty percent by the mid-1990s rather than ten percent. Thus, these results reinforce the key point that one cannot address determinacy issues only by focusing on the response coefficients of the central bank, instead we need to consider the interaction of the central bank's reaction function with trend inflation.

\section{E. Robustness Analysis}

The fact that higher trend inflation raises the likelihood of indeterminacy reflects the increased importance of forward-looking behavior in firms' price setting decisions. Specifically, when firms reset prices in the Calvo model, the weight placed on future profits depends strongly on how likely a firm is to not have altered its price by that period. Thus, greater price stickiness will naturally increase the sensitivity of reset prices to expectations of future macroeconomic variables. As a result, one would expect indeterminacy to become increasingly difficult to eliminate as the degree of price rigidity rises. 
To see whether this is indeed the case, we consider two alternative degrees of price stickiness. First, we follow Bils and Klenow (2004) who find that firms update prices every 4 to 5 months on average which corresponds to $\lambda=0.40$ in our model. Second, we follow Nakamura and Steinsson (2008) who find much longer durations of price spells ranging between 8 and 11 months on average. In this case, we set $\lambda=0.70$. We reproduce the determinacy results of section B. in Table 3 using the mixed Taylor rule for each time period. Under the Bils and Klenow case, we recover our baseline results of indeterminacy in the 1970s but determinacy after the Volcker disinflation. However, we can see that determinacy is more easily sustained under lower levels of price rigidity by the fact that the fraction of the empirical distribution yielding determinacy is consistently higher than in the baseline case. In addition, using this lower rate of price-stickiness implies that determinacy would have been achieved solely through the change in the Fed's response to macroeconomic variables. Using the degree of price stickiness from Nakamura and Steinsson moves all of the quantitative results in the opposite direction. For the pre-Volcker era, the results are qualitatively similar to our baseline findings, with indeterminacy occurring consistently at both inflation rates. However, with this higher degree of price stickiness, we now find that the current policy rule is likely inconsistent with determinacy: even at 3 percent inflation, less than 50 percent of the empirical distribution of Taylor rule estimates yields a determinate REE.

Clearly, the degree of price stickiness plays an important role in determinacy conditions. However, the importance of this variable is likely overestimated under Calvo pricing. This setup forces firms to place some weight on possible future outcomes in which their relative price would be so unprofitable that "real world" firms would likely choose to pay a menu cost and 
reset their price. ${ }^{22}$ An alternative approach to Calvo pricing is the staggered contracts approach of Taylor (1977) in which firms set prices for a pre-determined duration of time. This pricing assumption can loosely be thought of as a lower bound on forward-looking behavior (conditional on price durations) since it imposes zero weight on expected profits beyond those of the contract length in the firm's reset price optimization. We replicate our results using staggered pricing with firms setting prices for three quarters and display the results in Table 3. For the pre-Volcker era, the results again largely point to indeterminacy at high levels of inflation. However, the post-1982 policy rule is now consistent with determinacy at both 3 percent and 6 percent inflation rates. In fact, the results using staggered price setting with duration of 9 months are very close to those using Calvo price setting with average price duration of 5 months. We interpret Taylor pricing as setting a lower bound on determinacy issues (conditional on average price durations) and Calvo pricing an upper bound. Despite the sensitivity of determinacy results to these variations, what seems clear is that the U.S. economy was in an indeterminate region of the parameter space in the pre-Volcker era given the high average inflation of that time, but moved into the determinacy region after 1982. The relative importance of the decrease in trend inflation versus the changes in the Fed's response to macroeconomic conditions, on the other hand, is somewhat sensitive to the price-setting model and average price durations used.

A closely related issue is how to model price adjustment frictions faced by firms. A common extension is to model firms as facing sticky prices with indexation, i.e. allowing nonreoptimizing firms to automatically adjust their prices by some fraction of either last period's inflation or the trend inflation rate, thereby increasing the persistence of the inflation process (see

\footnotetext{
${ }^{22}$ Another way to see this limitation of the Calvo model is to note that using Nakamura and Steinsson rates of pricesetting, the Calvo model breaks down (i.e. $\gamma_{2} \geq 1$ ) at an inflation rate of 6.1 percent.
} 
Tack Yun (1996) and Lawrence Christiano et al (2005)). ${ }^{23}$ Ascari and Ropele (2009) have shown that allowing for indexation diminishes the determinacy issues that arise with positive trend inflation. The reason is that indexation decreases the devaluation of firms' reset prices that comes from positive trend inflation. In the special case of full indexation-firms raise their price fully with past inflation or the level of trend inflation-determinacy in the model becomes completely insensitive to trend inflation. We follow Yun (1996) and consider the case in which firms index their prices to trend inflation by some fraction $\omega$, where $0 \leq \omega \leq 1$.

We replicate our baseline empirical results on determinacy prospects based on our mixed Taylor rule estimates for each time period and for different levels of price indexation in Figure 5. ${ }^{24}$ Figure 5 makes clear that as indexation rises, the fraction of the empirical distribution of Taylor rule estimates consistent with determinacy also rises. Note that it takes fairly high levels of indexation to change our results substantially. For example, for the probability of determinacy to exceed 50 percent in the pre-1979 era at 6 percent inflation requires price indexation of more than 0.9. Thus, the result that the US economy was likely in an indeterminacy region preVolcker but not thereafter is robust to substantial levels of price indexation. However, the importance of taking into account positive trend inflation to reach this conclusion is also clearly illustrated in Figure 5. This can be seen by examining the results with full price indexation $(\omega=$ 1), in which case the supply-side of the model is observationally equivalent to the NKPC with

\footnotetext{
${ }^{23}$ Our baseline model does not include this feature for three reasons. First, the workhorse New Keynesian model is based only on price stickiness, making this the most natural benchmark for our analysis (Clarida et al (1999) and Michael Woodford (2003)). Second, any price indexation implies that firms are constantly changing prices, a feature strongly at odds with the empirical findings of Bils and Klenow (2004) and more recently Nakamura and Steinsson (2008), among many others. Third, while indexation is often included to replicate the apparent role for lagged inflation in empirical estimates of the NKPC (see Jordi Gali and Mark Gertler 1999), Cogley and Sbordone (2008) find no evidence of indexation after controlling for trend inflation.

${ }^{24}$ We continue to assume $\lambda=0.55$, although another drawback of introducing indexation into a model is that it is unclear how to link price stickiness from the micro data to price setting models with indexation in which firms are continuously changing prices.
} 
zero trend inflation. ${ }^{25}$ Determinacy is then driven almost exclusively by the Fed's response to inflation, yielding a probability of determinacy of more than 99 percent in the post-1982 era and approximately 55 percent in the pre-1979 era. The latter number reflects the fact that the point estimate of the Fed's long-run response to inflation is barely above one, so slightly more than half the draws from the empirical distribution will satisfy the Taylor principle and generate determinacy.

An important parameter in New Keynesian models is the elasticity of substitution $\theta$ which affects the degree of strategic complementarity in price setting As a robustness check, we consider the much lower value of $\theta=6$, which implies markups of 20 percent. With a lower elasticity of substitution, strategic complementarity in price setting is substantially reduced so that firms focus less on the pricing behavior of other firms and hence on trend inflation. Correspondingly, a lower $\theta$ tends to offset some of the effects of positive trend inflation on determinacy. As shown in Table 3, this does not alter our baseline result of indeterminacy in the 1970s switching to determinacy in the 1980s, but it does reduce the quantitative importance of trend inflation in accounting for the results, which is similar to our findings for reduced price stickiness as in Bils and Klenow (2004). However, with lower levels of strategic complementarity, one needs longer durations of price spells to match the persistence of macroeconomic data. We find that combinations of higher price stickiness (such as Nakamura and Steinsson values) with lower estimates of the elasticity of substitution yield essentially the same results as our baseline. $^{26}$

\footnotetext{
${ }^{25}$ This is why, for each time period, the 3 percent and 6 percent lines converge to the same value when $\omega=1$.

${ }^{26}$ We provide additional robustness checks in Coibion and Gorodnichenko (2008).
} 


\section{Conclusion}

This paper sheds new light on the sources of the significant decrease in macroeconomic volatility since the early 1980 s commonly referred to as the Great Moderation. We confirm the original insight of Clarida et al (2000) that the US economy moved from the indeterminacy region in the 1970s to determinacy since the early 1980s because of changes in monetary policy. Building on recent work showing that the Taylor principle does not guarantee determinacy when trend inflation is positive, we argue that despite substantial uncertainty about whether the Taylor principle was satisfied in the pre-Volcker era, the US economy was very likely subject to sunspot fluctuations in the 1970s given the high average rate of inflation over this time period, as well as the Fed's response to both inflation and the real side of the economy.

Our basic findings thus provide additional support for the well-known view that monetary policy changes have likely played an important element in accounting for the Great Moderation. However, the specific policy changes that we emphasize differ from the consensus monetary policy interpretation. One novel finding is that the Volcker disinflation very likely played a key role in restoring macroeconomic stability through its effect on the level of trend inflation. We also show using time-varying estimates of trend inflation that the increase in the Fed's target rate of inflation in the early 1970s contributed to the US economy moving into the indeterminacy region over this time period. Thus, our results strongly support studying the determinants of trend inflation, as in Primiceri (2006), Cogley et al (forthcoming) and Ireland (2007), and complement the recent finding, e.g. Cogley and Sbordone (2008), that accounting for trend inflation has important effects on estimates of the New Keynesian Phillips Curve.

In addition, while most research has emphasized the central bank's response to inflation as the key factor for determinacy, our results move the Fed's response to the real side of the economy to center stage, particularly when trend inflation is relatively high. In such a setting, 
responding to the output gap, even if perfectly measured, can be destabilizing, while responding to output growth is stabilizing. As a result, the substantial increase in the Federal Reserve's response to output growth since the Volcker disinflation has played a non-negligible role in restoring determinacy for the US economy. Our counterfactuals imply that if the Fed were to eliminate any response to the output gap, while maintaining a strong response to output growth, it could further improve determinacy prospects even at high (for the US) trend inflation rates. Furthermore, we show that with positive trend inflation policymakers should respond more aggressively to inflation to maintain a stable level of welfare even when the economy stays inside the determinacy region.

Our analysis also has implications for ongoing events in the U.S. economy. For example, some commentators have suggested that the severity of the current recession (which started in the fourth quarter of 2007) marks the end of the Great Moderation. However, every recession in the post-Volcker period has led to short-tem increases in volatility which subsequently reverted to lower levels as the economy recovered. The current recession is following a similar, albeit more pronounced, pattern, and volatility levels remain far below those of the 1970s. This is consistent with our understanding of the Great Moderation as a phenomenon determined to a significant extent by improved policy rather than luck. Indeed, the Fed's rapid response to the sharp contraction in the growth rate of output and its commitment to low trend inflation suggest that volatility is likely to return to low levels as the economy recovers. Furthermore, our results call for caution in evaluating recent arguments in favor of raising trend inflation to avoid hitting the zero bound on interest rates in the future, since such a policy action could precipitate a return to the volatility of the 1970s. However, further research is needed to fully understand and quantify the implications of positive trend inflation for macroeconomic dynamics in empirical and theoretical models as well as for normative analyses. 


\section{References}

Aruoba, S. Boragan, and Frank Schorfheide. 2009. "Sticky Prices versus Monetary Frictions: An Estimation of Policy Trade-offs.” National Bureau of Economic Research Working Paper 14870.

Ascari, Guido, and Tiziano Ropele. 2009. "Trend Inflation, Taylor Principle, and Indeterminacy.” Journal of Money, Credit and Banking, 48(1): 1557-1584.

Ascari, Guido, and Tiziano Ropele. 2007. "Optimal Monetary Policy under Low Trend Inflation.” Journal of Monetary Economics, 54(8): 2568-2583.

Basu, Susanto, and John G. Fernald, 1997. "Returns to Scale in U.S. Production: Estimates and Implications.” Journal of Political Economy, 105(2): 249-283.

Bils, Mark, and Peter J. Klenow, 2004. "Some Evidence on the Importance of Sticky Prices." Journal of Political Economy, 112(5): 947-985.

Boivin, Jean, and Marc Giannoni. 2006. "Has Monetary Policy Become More Effective?" Review of Economics and Statistics, 88(3): 445-462.

Boivin, Jean. 2006. "Has U.S. Monetary Policy Changed? Evidence from Drifting Coefficients and Real-Time Data.” Journal of Money, Credit and Banking, 38(5): 1149-1173.

Burnside, Craig. 1996. "Production Function Regressions, Returns to Scale, and Externalities." Journal of Monetary Economics, 37(2): 177-201.

Calvo, Guillermo. 1983. "Staggered Prices in a Utility-Maximizing Framework." Journal of Monetary Economics, 12(3): 383-98. 
Christiano, Lawrence, Martin Eichenbaum, and Charles Evans. 2005. "Nominal Rigidities and the Dynamic Effects of a Shock to Monetary Policy." Journal of Political Economy, 113(1): 1-45.

Clarida, Richard, Jordi Galí, and Mark Gertler. 1999. “The Science of Monetary Policy: A New Keynesian Perspective.” Journal of Economic Literature, 37(4): 1661-1707.

Clarida, Richard, Jordi Galí, and Mark Gertler. 2000. "Monetary Policy Rules and Macroeconomic Stability: Evidence and Some Theory." Quarterly Journal of Economics, 115(1): 147-180.

Cochrane, John. 2007. "Identification with Taylor Rules: A Critical Review." http://faculty.chicagobooth.edu/john.cochrane/research/Papers/identification_taylor_rule. pdf.

Cogley, Timothy, and Argia Sbordone. 2008. "Trend Inflation, Indexation and Inflation Persistence in the New Keynesian Phillips Curve." American Economic Review, 98(5): $2101-2026$.

Cogley, Timothy, Giorgio E. Primiceri, and Thomas J. Sargent. Forthcoming. "Inflation-Gap Persistence in the U.S.” American Economic Journal: Macroeconomics.

Coibion, Olivier, and Yuriy Gorodnichenko. 2008. "Monetary Policy, Trend Inflation and the Great Moderation: An Alternative Interpretation." National Bureau of Economic Research Working Paper 14621.

Davig, Troy, and Eric M. Leeper. 2007. "Generalizing the Taylor Principle." American Economic Review, 97(3): 607-635.

Gali, Jordi, and Mark Gertler. 1999. "Inflation Dynamics: A Structural Econometric Analysis." Journal of Monetary Economics, 44(2): 195-222. 
Gorodnichenko, Yuriy, and Matthew D. Shapiro. 2007. "Monetary Policy When Potential Output Is Uncertain: Understanding the Growth Gamble of the 1990s." Journal of Monetary Economics, 54(4): 1132-1162.

Gürkaynak, Refet, Brian Sack, and Eric T. Swanson. 2005. "Do Actions Speak Louder Than Words? The Response of Asset Prices to Monetary Policy Actions and Statements." International Journal of Central Banking, 1(1): 55-93.

Hornstein Andreas, and Alexander L. Wolman. 2005. "Trend Inflation, Firm-Specific Capital, and Sticky Prices." Federal Reserve Bank of Richmond Economic Quarterly, 91(4): 5783.

Ireland, Peter. 2004. "Technology Shocks in the New Keynesian Model.” Review of Economics and Statistics, 86(4): 923-936.

Ireland, Peter. 2007. "Changes in the Federal Reserve's Inflation Target: Causes and Consequences." Journal of Money, Credit, and Banking, 39(8): 1851-1882.

Justiniano, Alejandro, and Giorgio E. Primiceri. 2008. "The Time-Varying Volatility of Macroeconomic Fluctuations.” American Economic Review, 98(3): 604-641.

Kahn, James A., Margaret M. McConnell, and Gabriel Perez-Quirós. 2002. "On the Causes of the Increased Stability of the U.S. Economy." Economic Policy Review of the Federal Reserve Bank of New York, 8(1): 183-206.

Kiley, Michael E. 2007. “Is Moderate-to-High Inflation Inherently Unstable?" International Journal of Central Banking, 3(2): 173-201.

Kozicki, Sharon, and Peter A. Tinsley. 2009. "Perhaps the 1970s FOMC Did What It Said It Did." Journal of Monetary Economics, 56(6): 842-855.

Lubik, Thomas A., and Frank Schorfheide. 2004. "Testing for Indeterminacy: An Application to U.S. Monetary Policy.” American Economic Review, 94(1): 190-217. 
McConnell, Margaret, and Gabriel Perez-Quirós. 2000. “Output Fluctuations in the United States: What Has Changed since the Early 1980s?" American Economic Review, 90(5): 1464-76.

Nakamura, Emi, and Jón Steinsson. 2008. "Five Facts About Prices: A Reevaluation of Menu Cost Models." Quarterly Journal of Economics, 123(4): 1415-1464.

Orphanides, Athanasios, and John C. Williams. 2006. "Monetary Policy with Imperfect Knowledge." Journal of the European Economic Association, 4(2-3): 366-375.

Orphanides, Athanasios. 2001. "Monetary Policy Rules Based on Real-Time Data.” American Economic Review, 91(4): 964-985.

Orphanides, Athanasios. 2002. "Monetary Policy Rules and the Great Inflation." American Economic Review Papers and Proceedings, 92(2): 115-120.

Orphanides, Athanasios. 2003. "Historical Monetary Policy Analysis and the Taylor Rule." Journal of Monetary Economics, 50(5): 983-1022.

Orphanides, Athanasios. 2004. "Monetary Policy Rules, Macroeconomic Stability and Inflation: A View from the Trenches.” Journal of Money, Credit, and Banking, 36(2): 151-175.

Primiceri, Giorgio E. 2006. "Why Inflation Rose and Fell: Policymakers' Beliefs and US Postwar Stabilization Policy." Quarterly Journal of Economics, 121(3): 867-901.

Romer, Christina D., and David H. Romer. 2000. "Federal Reserve Information and the Behavior of Interest Rates.” American Economic Review, 90(3): 429- 457.

Romer, Christina D., and David H. Romer. 2002. "A Rehabilitation of Monetary Policy in the 1950's." American Economic Review, 92(2): 121-127.

Romer, Christina D., and David H. Romer. 2004. "A New Measure of Monetary Shocks: Derivation and Implications.” American Economic Review, 94(4): 1055-1084. 
Sargent, Thomas J. 1999. The Conquest of American Inflation, Princeton University Press, Princeton N.J.

Schmitt-Grohé, Stephanie, and Martín Uribe. 2007. "Optimal Simple and Implementable Monetary and Fiscal Rules.” Journal of Monetary Economics, 54(6): 1702-1725.

Sims, Eric. 2008. "Identification and Estimation of Interest Rate Rules in New Keynesian Models.” http://www.nd.edu/ esims1/taylor_rules.pdf.

Taylor, John B. 1977. “Staggered Wage Setting in a Macro Model.” American Economic Review Papers and Proceedings, 69(2): 108-113.

Taylor, John B. 1999. “An Historical Analysis of Monetary Policy Rules” in John B. Taylor (ed.) Monetary Policy Rules, University of Chicago Press.

Walsh, Carl E. 2003. "Speed Limit Policies: The Output Gap and Optimal Monetary Policies." American Economic Review, 93(1): 265-278.

Woodford, Michael. 2003. Interest and Prices: Foundations of a Theory of Monetary Policy, Princeton: Princeton University Press.

Yun, Tack. 1996. "Nominal Price Rigidity, Money Supply Endogeneity, and Business Cycles.” Journal of Monetary Economics, 37(2-3): 345-370. 
Figure 1: Determinacy in a New Keynesian Model with Calvo Pricing for Positive Trend Inflation Rates
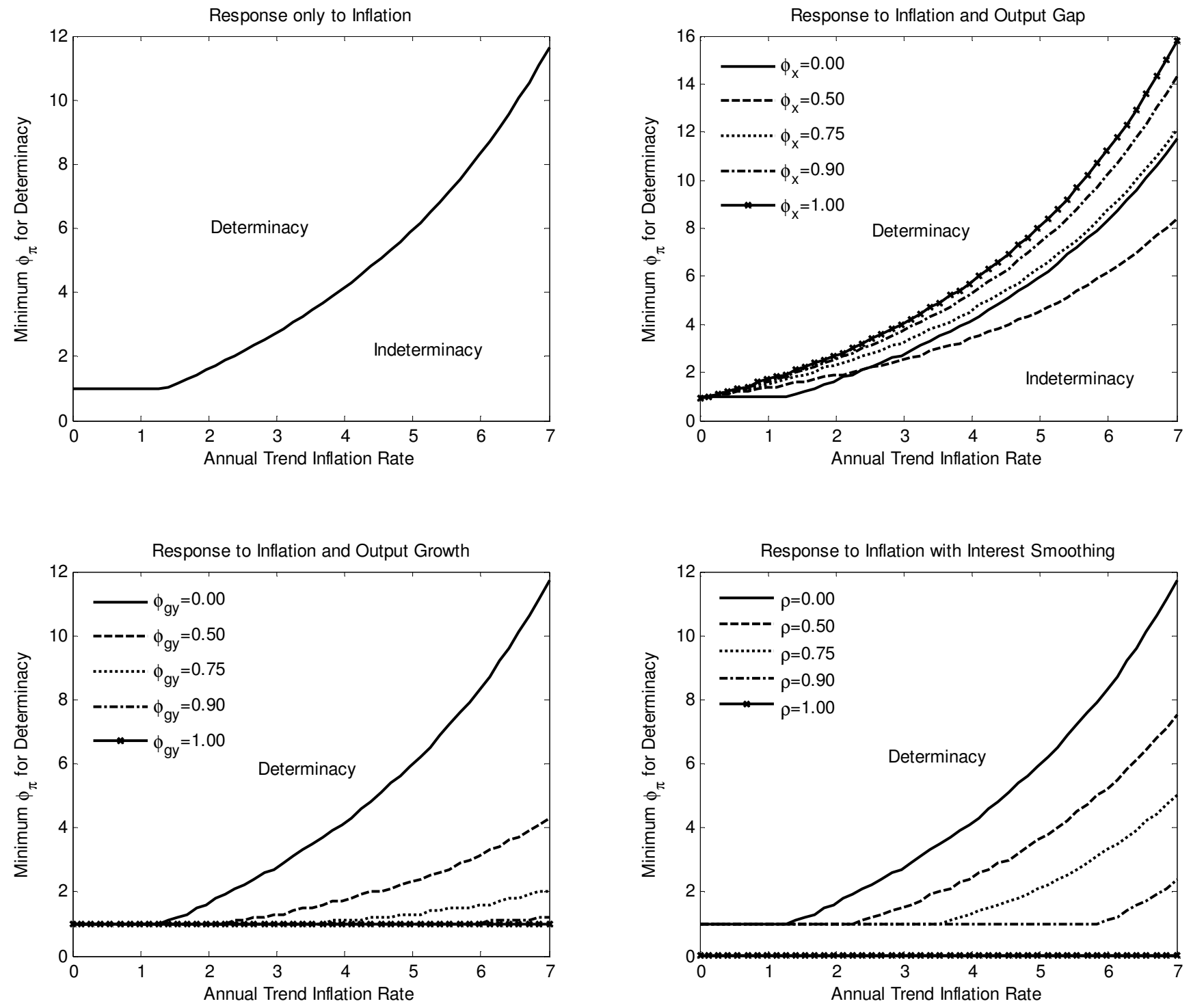

Notes: Trend inflation rate (percent per year) is on the horizontal axis. The minimum long-run response to inflation in the Taylor rule needed for determinacy is on the vertical axis. The top left panel uses the policy rule $r_{t}=\phi_{\pi} \pi_{t}$. The top right panel uses the policy rule $r_{t}=\phi_{\pi} \pi_{t}+\phi_{x} x_{t}$ where $x_{t}$ is the output gap. The bottom left panel uses the policy rule $r_{t}=\phi_{\pi} \pi_{t}+\phi_{g y} g y_{t}$ where $g y_{t}$ is the growth rate of output. The bottom right panel uses the policy rule $r_{t}=\rho r_{t-1}+(1-\rho) \phi_{\pi} \pi_{t}$ where $\rho$ is the degree of interest smoothing. For $\rho=1$, the Taylor rule is $r_{t}=r_{t-1}+\phi_{\pi} \pi_{t}$. The model and calibration of parameters are described in the text. 
Figure 2: The Effects of Trend Inflation within the Determinacy Region

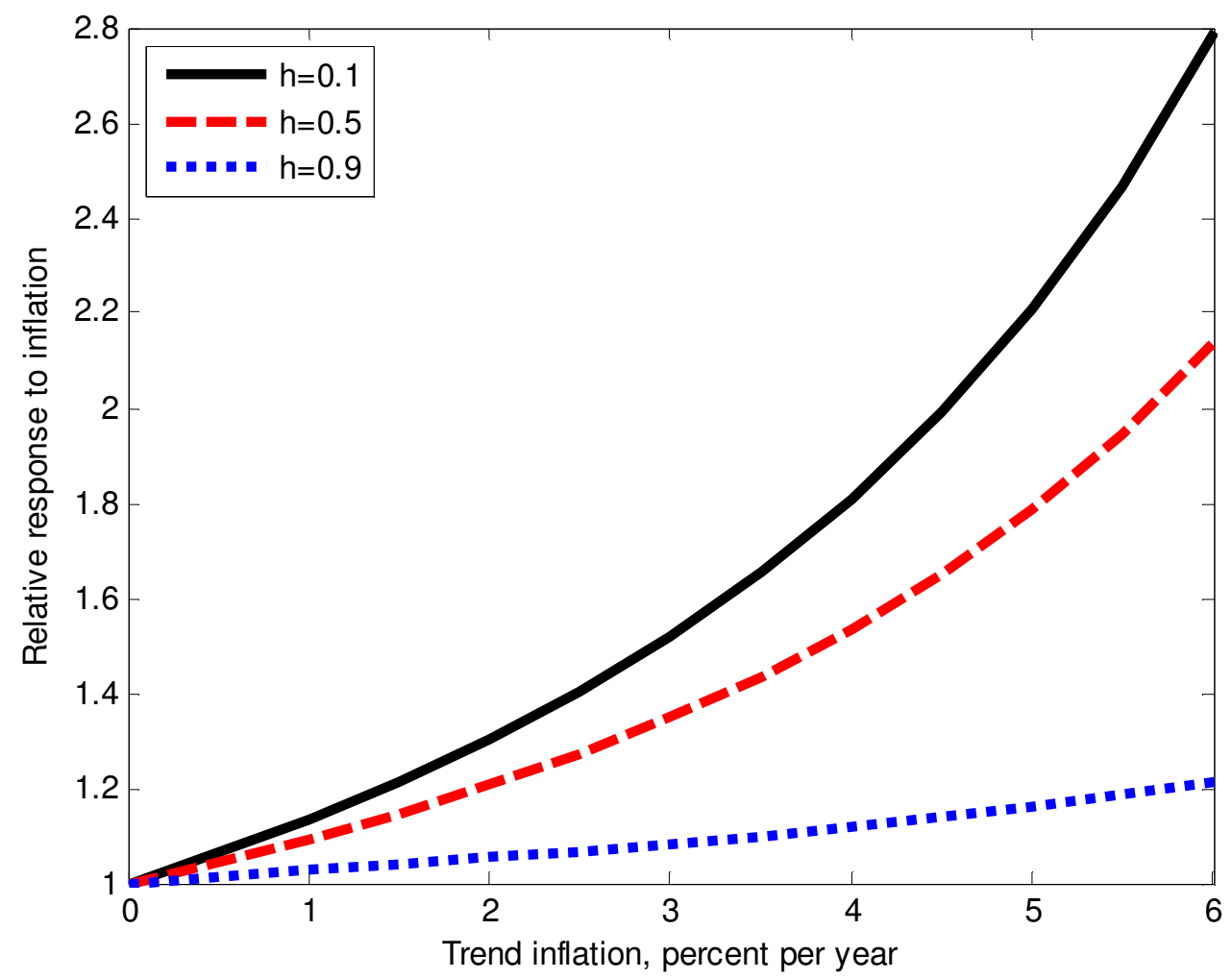

Notes: The figure plots the central bank's minimal response to inflation required to maintain a given level of utility for different levels of trend inflation relative to the minimal response to inflation necessary to maintain this level of utility for zero trend inflation. The policy rule is $r_{t}=\phi_{\pi} \pi_{t}$. The utility level is computed using the second order approximation to consumer utility with habit formation in consumption. Habit is governed by the parameter $h$. See text for further details. 
Figure 3: Time-Varying Parameter Estimates of the Taylor Rule
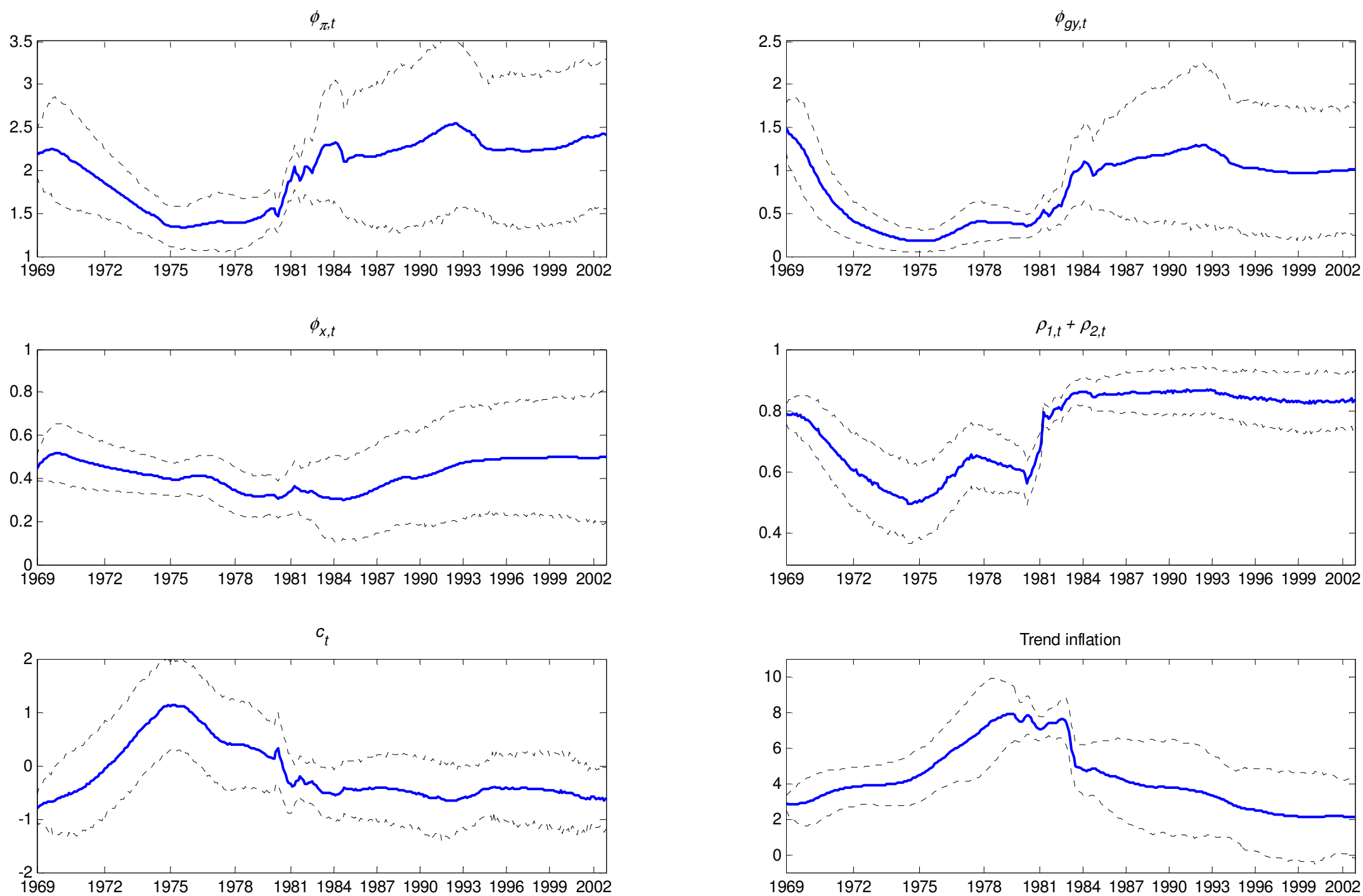

Notes: The figure presents time-varying parameter estimates of the Taylor rule, equation (7) in the text, under the assumption that parameters follow random walks. Smoothed estimates from the Kalman filter are reported. We allow for two breaks in volatility of the shocks to parameters: 1979 and 1982 . Dashed lines indicate one standard deviation confidence intervals. Trend inflation is extracted from the time-varying constant as explained in section III.D. Point estimates and confidence intervals are smoothed (moving average over five FOMC meetings) for expositional purposes. The sum of autoregressive coefficients in the Taylor rule is adjusted to quarterly frequency because pre-1979 and post-1982 periods have different frequency of FOMC meetings. 
Figure 4: Probability of Determinacy using Time-Varying Response Function by the Federal Reserve

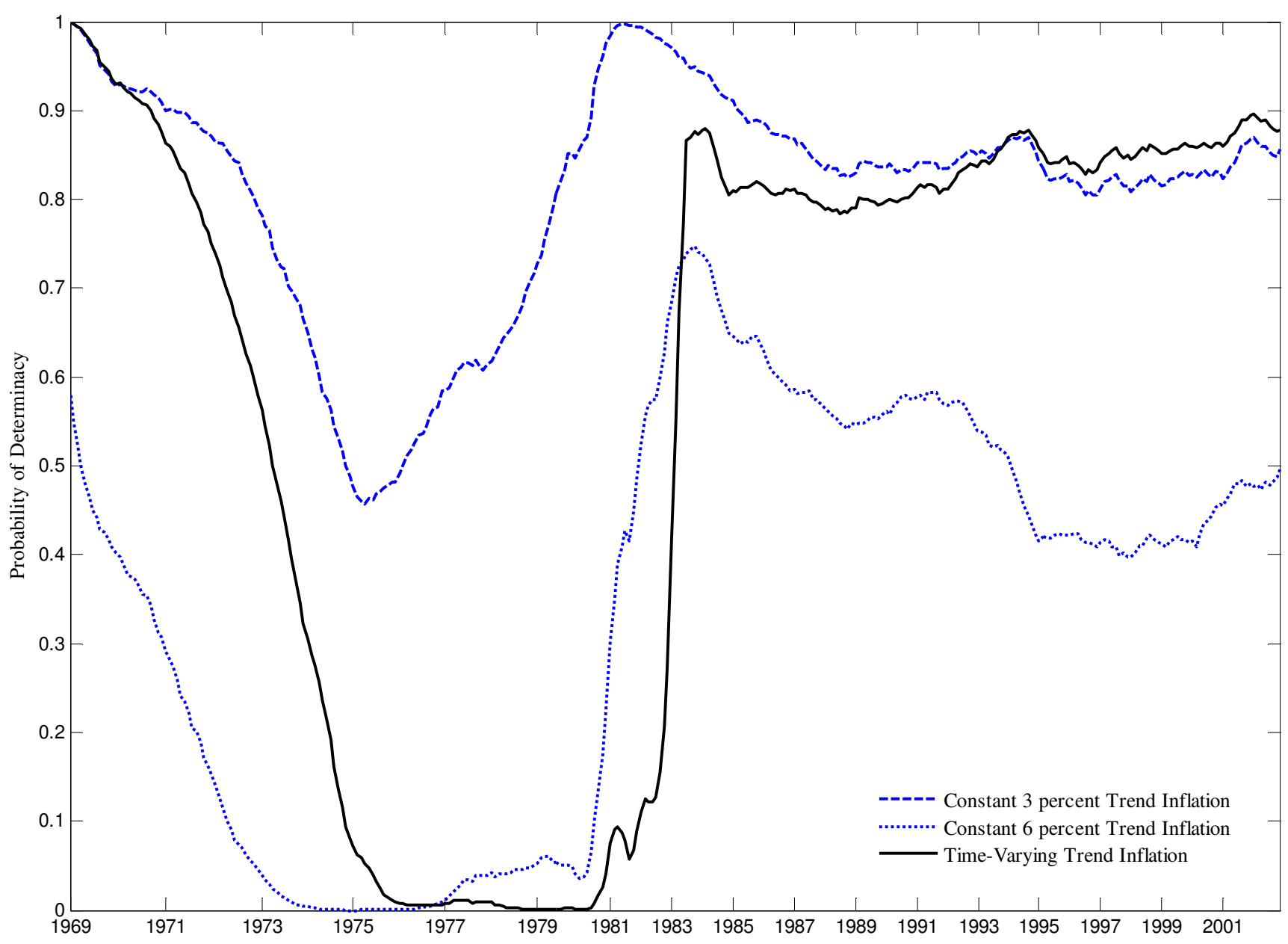

Notes: The figure presents the probability of determinacy implied by the distribution of time-varying parameters estimated in section III.B when combined with the baseline model of section I under various assumptions about trend inflation. The dashed (dotted) black line assumes a constant rate of trend inflation of 3 percent (6 percent), while the solid blue line uses the timevarying measure of trend inflation estimated in section III.B. The estimates are smoothed (moving average over five FOMC meetings) for expositional purposes. 
Figure 5: Effect of Price Indexation on Determinacy Results

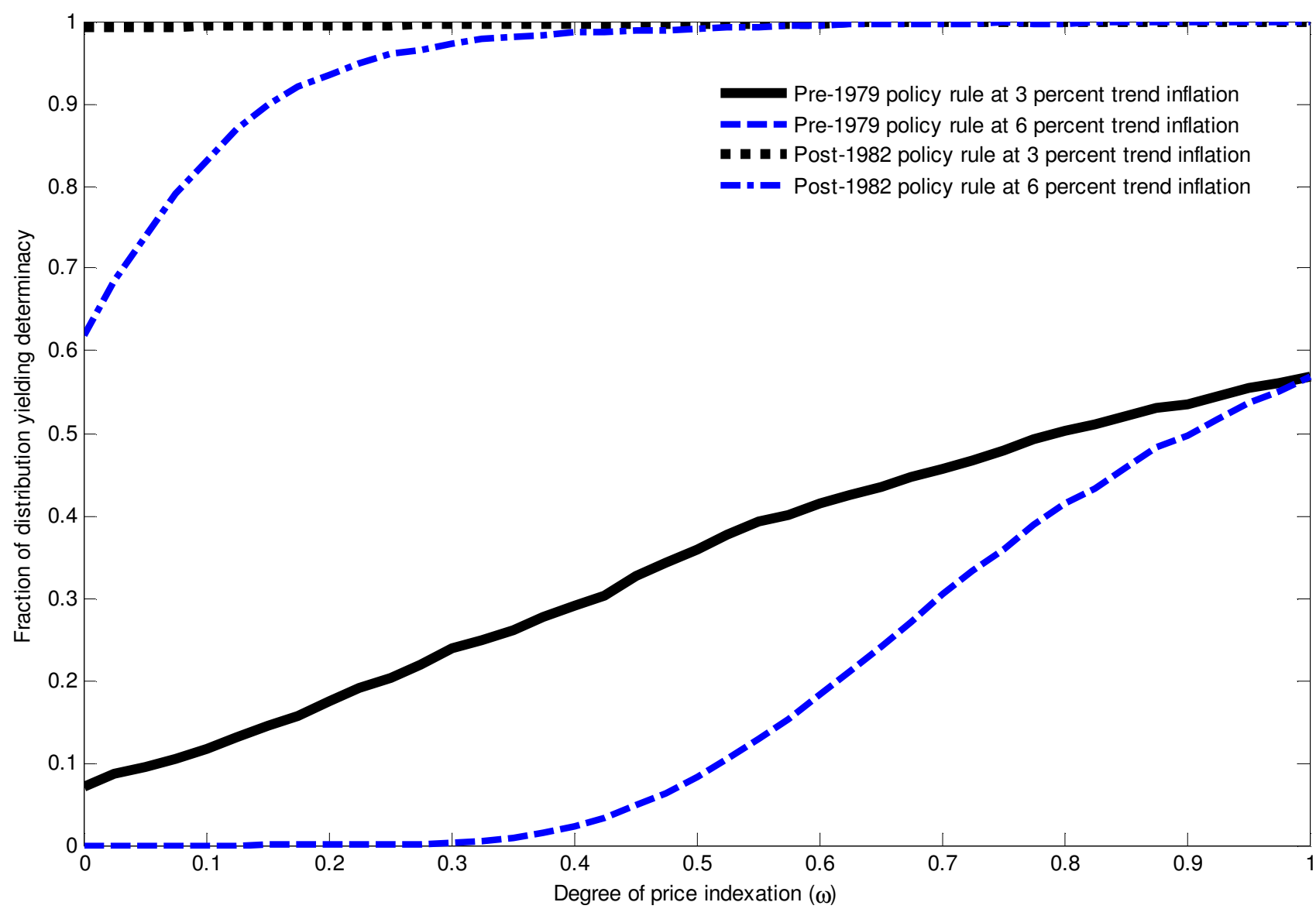

Notes: The figure plots the fraction of draws from the empirical distribution of coefficient estimates of the mixed Taylor rules from Table 1 in both time periods under alternative assumptions about trend inflation ( 3 percent or 6 percent) and different degrees of price indexation (indexed by $\omega$ ). 
Table 1: Estimates of Taylor Rule

\begin{tabular}{|c|c|c|c|c|c|c|c|c|c|}
\hline & \multicolumn{3}{|c|}{$\begin{array}{c}\text { Contemporaneous Taylor } \\
\text { Rule }\end{array}$} & \multicolumn{3}{|c|}{$\begin{array}{c}\text { Forward-Looking Taylor } \\
\text { Rule }\end{array}$} & \multicolumn{3}{|c|}{ Mixed Taylor Rule } \\
\hline & $\begin{array}{c}\text { pre } \\
1979\end{array}$ & $\begin{array}{l}\text { post } \\
1982\end{array}$ & $\begin{array}{l}p \text {-value } \\
\text { equality of } \\
\text { response }\end{array}$ & $\begin{array}{c}\text { pre } \\
1979\end{array}$ & $\begin{array}{l}\text { post } \\
1982\end{array}$ & $\begin{array}{l}p \text {-value } \\
\text { equality of } \\
\text { response }\end{array}$ & $\begin{array}{c}\text { pre } \\
1979\end{array}$ & $\begin{array}{l}\text { post } \\
1982\end{array}$ & $\begin{array}{l}p \text {-value } \\
\text { equality of } \\
\text { response }\end{array}$ \\
\hline$\overline{\phi_{t, \pi}}$ & $\begin{array}{c}0.79 \\
(0.27)\end{array}$ & $\begin{array}{c}1.58 \\
(0.51)\end{array}$ & 0.17 & & & & & & \\
\hline$\phi_{f, \pi}$ & & & & $\begin{array}{c}1.75 \\
(1.16)\end{array}$ & $\begin{array}{c}2.53 \\
(0.60)\end{array}$ & 0.53 & $\begin{array}{c}1.04 \\
(0.31)\end{array}$ & $\begin{array}{c}2.20 \\
(0.40)\end{array}$ & 0.03 \\
\hline$\phi_{t, g y}$ & $\begin{array}{c}0.04 \\
(0.13)\end{array}$ & $\begin{array}{c}2.21 \\
(0.82)\end{array}$ & 0.01 & & & & $\begin{array}{c}0.00 \\
(0.12)\end{array}$ & $\begin{array}{c}1.56 \\
(0.39)\end{array}$ & 0.00 \\
\hline$\phi_{f, g y}$ & & & & $\begin{array}{c}0.32 \\
(0.80)\end{array}$ & $\begin{array}{c}2.18 \\
(0.82)\end{array}$ & 0.10 & & & \\
\hline$\phi_{t, x}$ & $\begin{array}{c}0.48 \\
(0.12)\end{array}$ & $\begin{array}{c}0.44 \\
(0.16)\end{array}$ & 0.84 & & & & $\begin{array}{c}0.52 \\
(0.13)\end{array}$ & $\begin{array}{c}0.43 \\
(0.12)\end{array}$ & 0.42 \\
\hline$\phi_{f, x}$ & & & & $\begin{array}{c}1.03 \\
(0.70)\end{array}$ & $\begin{array}{c}0.59 \\
(0.22)\end{array}$ & 0.54 & & & \\
\hline$\rho_{1}$ & $\begin{array}{r}1.39 \\
(0.09)\end{array}$ & $\begin{array}{c}1.12 \\
(0.10)\end{array}$ & & $\begin{array}{c}1.34 \\
(0.09)\end{array}$ & $\begin{array}{c}1.28 \\
(0.09)\end{array}$ & & $\begin{array}{c}1.34 \\
(0.10)\end{array}$ & $\begin{array}{c}1.05 \\
(0.10)\end{array}$ & \\
\hline$\rho_{2}$ & $\begin{array}{l}-0.49 \\
(0.10)\end{array}$ & $\begin{array}{l}-0.18 \\
(0.10)\end{array}$ & & $\begin{array}{l}-0.39 \\
(0.09)\end{array}$ & $\begin{array}{l}-0.34 \\
(0.09)\end{array}$ & & $\begin{array}{l}-0.44 \\
(0.10)\end{array}$ & $\begin{array}{l}-0.13 \\
(0.10)\end{array}$ & \\
\hline$\rho_{1}^{q}+\rho_{2}^{q}$ & $\begin{array}{c}0.63 \\
(0.10) \\
\end{array}$ & $\begin{array}{r}0.90 \\
(0.05) \\
\end{array}$ & 0.00 & $\begin{array}{c}0.82 \\
(0.11) \\
\end{array}$ & $\begin{array}{c}0.87 \\
(0.06) \\
\end{array}$ & 0.34 & $\begin{array}{c}0.65 \\
(0.09) \\
\end{array}$ & $\begin{array}{c}0.86 \\
(0.04) \\
\end{array}$ & 0.02 \\
\hline$\overline{\mathrm{R}^{2}}$ & 0.967 & 0.984 & & 0.966 & 0.982 & & 0.966 & 0.985 & \\
\hline s.e.e. & 0.403 & 0.287 & & 0.409 & 0.308 & & 0.408 & 0.280 & \\
\hline AIC & \multicolumn{2}{|c|}{0.737} & & \multicolumn{2}{|c|}{0.808} & & \multicolumn{2}{|c|}{0.722} & \\
\hline SIC & \multicolumn{2}{|c|}{0.893} & & \multicolumn{2}{|c|}{0.965} & & \multicolumn{2}{|c|}{0.878} & \\
\hline$\underline{p \text {-val BG LM Test }}$ & \multicolumn{2}{|c|}{0.465} & & \multicolumn{2}{|c|}{0.583} & & \multicolumn{2}{|c|}{0.910} & \\
\hline \multicolumn{10}{|l|}{ Determinacy } \\
\hline 3 percent inflation & No & Yes & & No & Yes & & No & Yes & \\
\hline Fraction at 3 percent & 0.012 & 0.712 & & 0.480 & 0.977 & & 0.075 & 0.994 & \\
\hline 6 percent inflation & No & No & & No & Yes & & No & Yes & \\
\hline Fraction at 6 percent & 0.000 & 0.123 & & 0.119 & 0.494 & & 0.0 & 0.622 & \\
\hline
\end{tabular}

Notes: The top panel reports least squares estimates of the Taylor rule. Heteroskedasticity robust standard errors are in parentheses. $p$-value equality of response is the $p$-value of the null that the long-run responses are the same across the two periods. $\phi_{f, *}$ corresponds to the average forecast of the next 2 quarters (3 quarters for output gap) in Taylor rule estimated in equation (6). $\phi_{t, *}$ corresponds to $j=0$ in Taylor rule estimated in equation (6). $\rho_{1}^{q}+\rho_{2}^{q}$ is sum of autoregressive coefficients adjusted to quarterly frequency because pre-1979 and post-1982 periods have different frequency of FOMC meetings. AIC (SIC) is Akaike (Schwartz) Information Criterion for joint regression. p-val BG LM Test is the $p$-value for the Breusch-Godfrey Serial Correlation LM Test (using one lag). The bottom panel reports whether the estimated coefficients are consistent with a unique rational expectations equilibrium (REE) for trend inflation rates of 3 percent and 6 percent. 'Yes'/'No' shows whether there is a determinate REE when the policy reaction function rule is evaluated at point estimates of the Taylor rule. Fraction at $x$ percent is the fraction of draws from the distribution of estimated parameters which yield a unique REE at the specified inflation rate. 10,000 draws were used to compute the fraction of cases with indeterminate solutions. For each draw, parameters of a Taylor rule are taken from the joint asymptotically normal distribution based on least squares estimates of Taylor rules. 
Table 2: Fraction of determinate equilibria: Counterfactual Experiments

\begin{tabular}{|c|c|c|c|c|c|c|c|}
\hline & \multicolumn{5}{|c|}{ Taylor rule parameters } & \multicolumn{2}{|c|}{ Trend inflation } \\
\hline & $\phi_{\pi}$ & $\phi_{g y}$ & $\phi_{x}$ & $\rho_{1}$ & $\rho_{2}$ & 3 percent & 6 percent \\
\hline \multicolumn{8}{|l|}{ Pre-1979 period } \\
\hline Baseline Taylor Rule Estimates & 1.043 & -0.002 & 0.525 & 1.340 & -0.436 & 0.075 & 0.000 \\
\hline Switch Inflation Response & 2.201 & -0.002 & 0.525 & 1.340 & -0.436 & 0.674 & 0.003 \\
\hline Switch Interest Smoothing Parameters & 1.043 & -0.002 & 0.525 & 1.052 & -0.129 & 0.088 & 0.000 \\
\hline Switch Output Growth Response & 1.043 & 1.561 & 0.525 & 1.340 & -0.436 & 0.096 & 0.000 \\
\hline Switch Output Gap Response & 1.043 & -0.002 & 0.428 & 1.340 & -0.436 & 0.095 & 0.001 \\
\hline Zero Output Gap Response & 1.043 & -0.002 & $\mathbf{0}$ & 1.340 & -0.436 & 0.038 & 0.000 \\
\hline Zero Output Gap and Output Growth Response & 1.043 & $\mathbf{0}$ & $\mathbf{0}$ & 1.340 & -0.436 & 0.026 & 0.001 \\
\hline \multicolumn{8}{|l|}{ Post-1982 period } \\
\hline Baseline Taylor Rule Estimates & 2.201 & 1.561 & 0.428 & 1.052 & -0.129 & 0.994 & 0.622 \\
\hline Switch Inflation Response & 1.043 & 1.561 & 0.428 & 1.052 & -0.129 & 0.220 & 0.001 \\
\hline Switch Interest Smoothing Parameters & 2.201 & 1.561 & 0.428 & 1.340 & -0.436 & 0.993 & 0.619 \\
\hline Switch Output Growth Response & 2.201 & -0.002 & 0.428 & 1.052 & -0.129 & 0.913 & 0.264 \\
\hline Switch Output Gap Response & 2.201 & 1.561 & 0.525 & 1.052 & -0.129 & 0.988 & 0.333 \\
\hline Zero Output Gap Response & 2.201 & 1.561 & $\mathbf{0}$ & 1.052 & -0.129 & 0.998 & 0.987 \\
\hline Zero Output Gap and Output Growth Response & 2.201 & $\mathbf{0}$ & $\mathbf{0}$ & 1.052 & -0.129 & 0.954 & 0.127 \\
\hline
\end{tabular}

Notes: This table lists determinacy results for the 1969-1978 period and the 1983-2002 period for trend inflation rates of 3 percent and 6 percent. Baseline Taylor Rule Estimates refers to the case in which the estimated parameters of the mixed Taylor rule from Table 1 are plugged into the model. Switch means using the coefficient from the other period's estimated rule and keeping the other parameters of the rule unchanged. Parameter values in bold show the coefficient for which the value is modified. 10,000 draws were used to compute the fraction of cases with determinate solutions. For each draw, parameters of a Taylor rule are taken from the joint asymptotically normal distribution based on least squares estimates of Taylor rules. 
Table 3. Robustness of Determinacy Results

\begin{tabular}{ccccc}
\multicolumn{2}{c}{ Pre-1979 period } & & \multicolumn{2}{c}{ Post-1982 period } \\
\cline { 1 - 1 } Determinacy & Fraction of & & & Fraction of \\
at point & determinate & & Determinacy & determinate \\
estimates & equilibria given & & at point & equilibria given \\
& sampling & & estimates & sampling \\
& uncertainty & & & uncertainty \\
\hline
\end{tabular}

\section{Bils and Klenow (2004) Case (change prices every 5 months)}

$\begin{array}{llllr}3 \text { percent inflation } & \text { No } & 0.169 & \text { Yes } & 0.995 \\ 6 \text { percent inflation } & \text { No } & 0.000 & \text { Yes } & 0.933\end{array}$

Nakamura and Steinsson (2008) Case (change prices every 10 months)

3 percent inflation

6 percent inflation

No $\quad 0.000$

No $\quad 0.000$

$\begin{array}{ll}\text { No } & 0.309 \\ \text { No } & 0.071\end{array}$

3 percent inflation

6 percent inflation

\section{Lower elasticity of substitution $\theta=6$}

3 percent inflation

$\begin{array}{ll}\text { No } & 0.373 \\ \text { No } & 0.101\end{array}$

Yes

0.999

Yes

0.996

Lower elasticity of substitution $\theta=6$ and Nakamura and Steinsson (2008) Case

$\begin{array}{lllll}3 \text { percent inflation } & \text { No } & 0.080 & \text { Yes } & 0.994 \\ 6 \text { percent inflation } & \text { No } & 0.000 & \text { Yes } & 0.602\end{array}$

Notes: The table presents robustness results of determinacy from Table 1. 'Yes'/'No' shows whether there is a determinate rational expectations equilibrium when the policy reaction function is evaluated at point estimates of the Taylor rule. 10,000 draws were used to compute the fraction of cases with determinate solutions. For each draw, parameters of a Taylor rule are taken from the joint asymptotically normal distribution based on least squares estimates of Taylor rules. 